
\title{
Reseacch S Suare \\ Green and Resilient Mixed Supply Chain Network Design to Reduce Environmental Impacts and Deal With Disruptions
}

Mohammad Mahdi Vali-Siar

KN Toosi University of Technology Faculty of Industrial Engineering

Emad Roghanian (D e_roghanian@kntu.ac.ir)

KN Toosi University of Technology Faculty of Industrial Engineering

\section{Research Article}

Keywords: Green Supply chain design, environmental aspects, reverse logistics, resilience, disruption, metaheuristics

Posted Date: January 21st, 2022

DOI: https://doi.org/10.21203/rs.3.rs-1140812/v1

License: (c) (i) This work is licensed under a Creative Commons Attribution 4.0 International License.

Read Full License 


\title{
Green and resilient mixed supply chain network design to reduce environmental impacts and deal with disruptions
}

\author{
Mohammad Mahdi Vali-Siar, Emad Roghanian* \\ Department of Industrial Engineering, K. N. Toosi University of Technology, Tehran, Iran.
}

\begin{abstract}
Disruption risks may halt or adversely affect supply chain operations and can lead to deviations in its objectives. One of the most important objectives of the supply chain which can be adversely affected by disruptions, is environmental objective. Therefore, considering supply chain resilience and environmental aspects simultaneously is of great importance. In this paper, the problem of designing a green and resilient mixed open and closed-loop supply chain network under operational and disruption risks has been studied. A bi-objective mixed integer linear programming model is proposed to formulate the problem. Some resilience strategies are applied to deal with disruption risks and enhance supply chain resilience. In order to overcome the complexity of the problem and solve the problems with medium and large sizes, a new meta-heuristic algorithm called multi-objective hybrid Ant-colony optimization and teaching and learning based optimization (ACO-TLBO) has been proposed and compared with two hybrid metaheuristics and the augmented $\varepsilon$-constraint method through various test problems. The outcomes showed that the ACO-TLBO algorithm is very efficient in obtaining high-quality Pareto solutions and is the best method among the proposed methods. Also, in order to show the applicability of the problem and validate the model and solution methods, a real case study in the tire industry has been presented and analyzed. The results of analyses demonstrate the high effectiveness of resilience strategies and the necessity of joint consideration of resilience and greenness in the supply chain design.
\end{abstract}

Keywords: Green Supply chain design, environmental aspects, reverse logistics, resilience, disruption, metaheuristics

\section{Introduction}

Today's organizations seek to exploit the advantages of right supply chain (SC) management in order to maintain their position in the market, create competitive advantages, decrease costs, and generally speaking, manage their supply chain efficiently. The design of the supply chain network plays a crucial role in the supply chain management since it determines the physical structure of the supply chain and makes decisions on issues such as choosing location, number, and capacity of facilities, selecting suppliers, and the like (Govindan et al., 2017).

Climate change poses one of the greatest threats to human life (Meng et al., 2020). Global population growth has led to an increase in energy consumption due to the necessity of responding to growing demands (Ramezanian et al., 2019) and consequently has accelerated climate change and global warming. This, along with issues such as limitations and increasing consumption of non-renewable natural resources, environmental pollution, adoption of relevant laws in many countries, and other concerns, have attracted the attention of researchers and decision-makers to the issue of reverse logistics (Soleimani et al., 2017). Supply chain network structures can be divided into three groups: forward supply chains, reverse supply chains, and supply chains that include both forward and reverse flows. The latter can also be divided into three categories of open-loop, closed-loop, and mixed open and closed-loop (Van Engeland et al., 2020). In mixed supply chains, some of recyclable materials and products remain and are used within the supply chain, while the rest leave the supply chain and enter other supply chains for similar or different purposes (Salema et al., 2007). Reverse logistics can improve the environmental aspect of sustainability because they are very effective in reducing energy consumption, material consumption, and environmental pollution.

Supply chains are exposed to different risks that can be categorized as operational risks and disruptions. Operational risks are rooted in the inherent uncertainty of supply chains, which include uncertainties in supply, demand, delivery times, shipping times, and costs. Disruptions may occur in parts of the supply chain due to natural disasters (such as floods and earthquakes), intentional or unintentional human actions (such as strikes, wars, and terrorist attacks), or

\footnotetext{
* Corresponding author.

Email addresses: mvalisiar@email.kntu.ac.ir(M.M.Vali-Siar), e_roghanian@kntu.ac.ir (E. Roghanian),
} 
technical factors (such as equipment and information system failures) (Sabouhi et al., 2018). These disruptions have a major impact on the supply chain and adversely affect the objectives and the performance of the supply chain (Torabi et al., 2016). New supply chains are more likely to face disruptions because they have greater lengths and are more complex (Namdar et al., 2018). The Covid-19 pandemic is currently a worldwide disruption, which is one of the biggest disruptions in recent decades and has had many negative effects on supply chains around the world. The performance and responsiveness of SCs have been degraded, because of delivery delays, lack of raw materials, and disturbance in logistics systems caused by the pandemic (Karmaker et al., 2021). This disruption has increasingly challenged supply chain resilience (Ivanov and Dolgui, 2020), which is the ability of the supply chain to cope with, adapt to, and restore to pre-disruption or a new desired state to respond to demand and maintain proper performance (Hosseini et al., 2019). Supply chain resilience is highly dependent on its design, and companies with better supply chain designs are often more resilient to disruptions (Klibi et al., 2010).

In general, sustainability and resilience should be considered together to assure the survival of the system by exploiting the synergy of these two concepts. On the other hand, supply chain must be resilient in order to maintain its proper sustainability performance, including in the environmental dimension (Zare Mehrjerdi, and Shafiee, 2021). In this paper, an integrated green and resilient mixed open and closed-loop supply chain network design (SCND) and redesign problem is studied, and a novel bi-objective mathematical model is developed with the objectives of maximizing the total profit of SC and minimizing the SC negative environmental impacts. In order to enhance the resilience of the network against disruptions, some resilience strategies are applied. Three hybrid metaheuristics are proposed to handle the computational complexity of the problem. Also, a real case study and various test problems are provided to verify the mathematical model and solution methods and show the applicability of the studied problem and analyze it.

The other sections of the paper are as follows. In the "Literature review" section, the literature on green SCND, resilient SCND and green-resilient SCND are reviewed. The "Problem definition and mathematical modeling" section presents the problem definition and the proposed mathematical model. The solution methods are described in the "Solution methods" section. The case study, test problems and the computational results and analyses are provided in the section of "Computational results and analyses". Finally, the conclusions and directions for future research are given in the section of "Conclusion".

\section{Literature review}

In this section, the literature related to the problem studied in this paper is briefly reviewed. The literature review is presented in 4 subsections. The first three subsections present the literature review on green SCND, green-resilient SCND and integrated green and resilient SCND. The last subsection provides the research gaps and expresses the contributions of our paper.

\section{Green supply chain network design}

Given that the literature on green SCND is vast, here, the papers are that more relevant to our paper are reviewed. For this purpose, in this subsection, we concentrate on papers that have studied green supply chain design with considering reverse logistics.

Zohal and Soleimani (2016) studied a green closed loop SCND problem in gold industry. They developed a multiobjective mixed integer linear programming model for the problem. The objective functions were minimizing cost, maximizing income and minimizing $\mathrm{CO}_{2}$ emissions. Nurjanni et al. (2017) presented a bi-objective mathematical model for green closed-loop SCND problem. The considered objectives were minimization of costs and environmental impacts. Mohtashami,et al. (2020) used queuing system in green closed-loop supply chain design problem to minimize negative environmental impacts and energy consumption. There are other similar works in this literature such as the papers of Sadeghi Rad and Nahavandi (2018) and Mardan et al. (2019).

The mentioned papers did not consider uncertainty in their problem. Some researchers studied closed-loop green SCND under uncertainty. Soleimani et al. (2017) proposed a tri-objective mathematical model for green SCND under demands and social impacts uncertainties. The objective functions were maximizing profit, maximizing satisfied demands and minimizing lost work days. Ghomi-Avili et al., (2018) studied competitive green closed-loop SCND in the presence of disruptions for suppliers. The authors developed a bi-objective mathematical model whose objectives were maximizing supply chain profit and minimizing CO2 emissions. Zarrat Dakhely Parast et al. (2021) studied a green supply chain design problem with forward and reverse flows. They considered location, routing and inventory decisions in their problem. Other research papers on green closed-loop SCND under uncertainty can be found in the works of Zhen et al. (2019) and Boronoos et al. (2021). 


\section{Resilient supply chain network design}

Resilient supply chain network design is a growing research field. Especially in recent months, due to the outbreak of Covid-19 pandemic disease, its importance has become more and more realized.

The vast majority of studies in the field of resilient SCND have used resilience strategies to deal with disruptions. Multiple sourcing as the most well-known strategy has been sued by Peng et al. (2011), Hasani and Khosrojerdi (2016), Rezapour et al. (2017), Sabouhi et al. (2018), Bottani et al. (2019), Sabouhi et al. (2020) and Gholami-Zanjani et al. (2021a). This strategy allows a downstream facility to be served by two or more upstream facilities. When one or more upstream facilities cannot satisfy the demands of downstream facilities partially or completely, other upstream facilities can be replaced and avoid interruptions in operations and more damages. In facility fortification strategy, facilities are fortified against disruptions based on some fortification levels. With increasing the level of fortification, the resistance of facility increases, and of course, with increasing the level of fortification, related costs increase (Fattahi et al., 2017). The works of Azad et al. (2013), Jabbarzadeh et al. (2016), Fattahi et al. (2017), Gholami-Zanjani et al. (2021a) have utilized facility fortification as a resilience strategy. Using backup facilities is another resilience strategy used in some papers such as Salehi Sadghiani et al. (2015), Jabbarzadeh et al. (2016), Sabouhi et al. (2020) and Gholami-Zanjani et al. (2021a). Using this strategy will cause similar backup facilities to be replaced if one or more facilities fail, and activities will continue as possible. Capacity expansion strategy allows adding extra capacity to a facility when its capacity is decreased due to a disruption. Sabouhi et al. (2020) and Gholami-Zanjani et al. (2021a) have applied this strategy in their studies. Lateral transshipment strategy allows transshipping products and materials between facilities in a same echelon. With using this strategy products can be transferred to disrupted facilities when needed. This strategy is used in the papers of Jabbarzadeh et al. (2018b) and sabouhi et al. (2020). Keeping inventory is another main resilience strategy that helps prevent shortages in materials and products when disruption occurs. Hasani and Khosrojerdi (2016) and Sabouhi et al. (2018) Are examples of research that have applied this strategy. There are other strategies such as alternative bill of material adaption (Hasani and Khosrojerdi, 2016) and dual channel distribution (Sabouhi et al., 2020) which can be useful according to the structure of the problem.

In terms of the network structure, most of the research considered the traditional design of the forward supply chain. Among the supply chain network design studies, Jabbarzadeh et al. (2018b) studied resilient closed-loop SCND under disruption risks. They presented a stochastic robust optimization model to formulate the problem. Vali-Siar and Roghanian (2020) investigated the problem of mixed open and closed-loop SCND under operational and disruption risks. They developed a new mathematical model with the objective of maximizing SC profit. Multiple sourcing, facility fortification, capacity expansion, dual-channel distribution and price adjustment were used as resilience strategies. Recently, Zare Mehrjerdi and Shafiee (2021) worked on sustainable and resilient closed-loop SCND and applied multiple sourcing and information sharing strategies to increase the SC resilience.

Some researchers considered other concepts besides resilience in their SCND problem. Fattahi et al. (2017) and Sabouhi et al. (2020) studied resilient and responsive SCND problem. Rezapour et al. (2017) and Ghavamifar et al. (2018) raised the issue of competition in resilient SCND problem under disruptions. The problem of resilient SCND with considering environmental issues or so-called green and resilient SCND is another important topic that is investigated in the nest subsection.

\section{Green and resilient supply chain network design}

Due to the importance of considering environmental issues and the effects of disruptions on supply chain objects such as environmental objectives, considering resilience and environmental issues simultaneously is very important. The topic of green and resilient SCND seems to be a growing field of research, and there are still some issues to be studied more, especially the SCs with reverse logistics. Fahimnia et al. (2018) used an environmental performance scoring approach and a robustness measure to consider environmental issues and resilience in the SCND problem. They presented a single-objective mathematical model. Mohammed et al. (2019) studied green and resilient SCND problem. They developed a tri-objective mathematical model with the objectives of minimization of total cost, minimization of $\mathrm{CO}_{2}$ and maximization of $\mathrm{SC}$ resilience. Some researchers utilized resilience strategies to mitigate disruptions. Hasani et al. (2021) used facility fortification, facility dispersion, semi-finished goods production, and multiple sourcing strategies for designing resilient and green SCND problem. Recently, Gholami-Zanjani et al. (2021b) used multiple sourcing and backup suppliers for designing green and resilient meat SCND.

The above-mentioned studies did not consider reverse logistics. Yavari and Zaker (2019) proposed a bi-objective MILP model for resilient and green closed-loop SCND Problem in the dairy industry. They applied interdependent two-layer structure for considering disruption in the electric power network supplying the power of the SC. The objective functions of their model were minimizing SC costs and carbon emissions. There is another category of research papers that studies sustainability and resilience in their problem. The papers of Jabbarzadeh et al. (2018a), 

et al. (2021) studied sustainable and resilient SCND problem.

\section{Research Gaps}

In Table 1, the related papers are summarized and their main characteristics are specified. According to the table, it can be seen that the issue of resilient mixed SCND has not been studied in the articles except for the previous work of the authors. Secondly, the problem of SCND with joint consideration of resilience and environmental issues in networks with reverse logistics has been only addressed in one paper whose network structure is closed-loop. Also, the simultaneous consideration of resilience, greenness and responsiveness has not been studied in previous studies. Moreover, only two papers have studied responsive resilient SCND and more research should be done in this field. As can be seen from Table 1, the problem of resilient supply chain network redesign has been discussed in only one paper, and there is a research gap in this area as well. Overall, to the best of our knowledge, no work has been done on integrated green, resilient and responsive mixed SCND. Based on these descriptions the main contributions of this paper are as follows:

- Presenting a novel mathematical model for the problem of mixed open and closed-loop supply chain network design

- Considering resilience, greenness and responsiveness simultaneously in the considered problem

- Considering the probable occurrence of disruptions for all facilities of supply chain network as well as vehicles, and applying several resilience strategies, such as using backup vehicles for dealing with disruptions

- $\quad$ Paying attention to both supply chain design and redesign concepts

- Proposing a novel hybrid metaheuristic to deal with problem complexity and comparing it with two other hybrid metaheuristic

- Analyzing the problem and solution methods via a real case study in the tire industry and various test problems 
Table 1 Characteristics of the related research

\begin{tabular}{|c|c|c|c|c|c|c|c|c|c|c|c|c|c|c|c|c|c|c|c|c|c|}
\hline \multirow{2}{*}{ Research } & \multicolumn{2}{|c|}{$\begin{array}{l}\text { Problem } \\
\text { approach }\end{array}$} & \multicolumn{4}{|c|}{ SC characteristics } & \multicolumn{3}{|c|}{ Network structure } & \multicolumn{3}{|c|}{ Reverse logistics operations } & \multicolumn{7}{|c|}{ Decisions } & \multirow{2}{*}{$\begin{array}{l}\text { Uncertainty } \\
\text { approach }\end{array}$} & \multirow{2}{*}{$\begin{array}{l}\text { Solution } \\
\text { method }\end{array}$} \\
\hline & Design & Redesign & Gr & Rs & $\mathrm{Rp}$ & Oth & $\mathrm{F}$ & $\mathrm{OL} / \mathrm{CL}$ & Mixed & Col & Rec & Rem & LA & SS & $\mathrm{Fl}$ & $\mathrm{CF}$ & $\operatorname{Pr}$ & $\mathrm{VS}$ & Oth & & \\
\hline Peng et al. (2011) & $\checkmark$ & & & $\checkmark$ & & & $\checkmark$ & & & & & & $\checkmark$ & & $\checkmark$ & & & & & $\overline{\mathrm{SP}}$ & MHeu, CS \\
\hline Azad et al. (2013) & $\checkmark$ & & & $\checkmark$ & & & $\checkmark$ & & & & & & $\checkmark$ & & $\checkmark$ & & & & & -- & $\mathrm{BD}, \mathrm{CS}$ \\
\hline Salehi Sadghiani et al. (2015) & $\checkmark$ & & & $\checkmark$ & & & $\checkmark$ & & & & & & $\checkmark$ & & $\checkmark$ & & & & $\checkmark$ & RO & CS \\
\hline Hasani and Khosrojerdi (2016) & $\checkmark$ & & & $\checkmark$ & & & $\checkmark$ & & & & & & $\checkmark$ & $\checkmark$ & $\checkmark$ & & & & $\checkmark$ & RO & MHeu \\
\hline Jabbarzadeh et al. (2016) & $\checkmark$ & & & $\checkmark$ & & & $\checkmark$ & & & & & & $\checkmark$ & & $\checkmark$ & & & & & RO & LR, CS \\
\hline Zohal and Soleimani (2016) & $\checkmark$ & & $\checkmark$ & & & & & $\checkmark$ & & $\checkmark$ & $\checkmark$ & & $\checkmark$ & & $\checkmark$ & & & & & -- & MHeu, CS \\
\hline Nurjanni et al. (2017) & $\checkmark$ & & $\checkmark$ & & & & & $\checkmark$ & & $\checkmark$ & $\checkmark$ & $\checkmark$ & $\checkmark$ & & $\checkmark$ & & & & & -- & WM, Oth \\
\hline Fattahi et al. (2017) & $\checkmark$ & & & $\checkmark$ & $\checkmark$ & & $\checkmark$ & & & & & & $\checkmark$ & & $\checkmark$ & & & & & SP & $\mathrm{CS}$ \\
\hline Soleimani et al. (2017) & $\checkmark$ & & $\checkmark$ & & & & & $\checkmark$ & & $\checkmark$ & $\checkmark$ & & $\checkmark$ & & $\checkmark$ & & & & & FP & MHeu, CS \\
\hline Rezapour et al. (2017) & $\checkmark$ & & & $\checkmark$ & & $\checkmark$ & $\checkmark$ & & & & & & $\checkmark$ & & $\checkmark$ & $\checkmark$ & $\checkmark$ & & & SP & $\mathrm{CS}$ \\
\hline Ghavamifar et al. (2018) & $\checkmark$ & & & $\checkmark$ & & $\checkmark$ & $\checkmark$ & & & & & & $\checkmark$ & & $\checkmark$ & & $\checkmark$ & & $\checkmark$ & SP & BD, Oth \\
\hline Ghomi-Avili et al. (2018) & $\checkmark$ & & $\checkmark$ & & & $\checkmark$ & & $\checkmark$ & & $\checkmark$ & $\checkmark$ & & $\checkmark$ & $\checkmark$ & $\checkmark$ & & $\checkmark$ & & $\checkmark$ & PP & CS, Oth \\
\hline Sabouhi et al (2018) & $\checkmark$ & & & $\checkmark$ & & & $\checkmark$ & & & & & & $\checkmark$ & $\checkmark$ & $\checkmark$ & & & & $\checkmark$ & SP & $\mathrm{CS}$ \\
\hline Sadeghi Rad and Nahavandi (2018) & $\checkmark$ & & $\checkmark$ & & & & & $\checkmark$ & & $\checkmark$ & $\checkmark$ & $\checkmark$ & $\checkmark$ & $\checkmark$ & $\checkmark$ & & & & $\checkmark$ & -- & CS \\
\hline Jabbarzadeh et al. (2018a) & $\checkmark$ & & & $\checkmark$ & & $\checkmark$ & $\checkmark$ & & & & & & $\checkmark$ & $\checkmark$ & $\checkmark$ & $\checkmark$ & & & & SP & $\mathrm{CS}$ \\
\hline Jabbarzadeh et al. (2018b) & $\checkmark$ & & & $\checkmark$ & & & & $\checkmark$ & & $\checkmark$ & & & $\checkmark$ & & $\checkmark$ & & & & $\checkmark$ & SP & $\mathrm{LR}, \mathrm{CS}$ \\
\hline Mardan et al. (2019) & $\checkmark$ & & $\checkmark$ & & & & & $\checkmark$ & & & & $\checkmark$ & $\checkmark$ & $\checkmark$ & $\checkmark$ & & & & & -- & $\mathrm{BD}, \mathrm{CS}$ \\
\hline Mohammed et al. (2019) & $\checkmark$ & & $\checkmark$ & $\checkmark$ & & & $\checkmark$ & & & & & & $\checkmark$ & $\checkmark$ & & & & & $\checkmark$ & FP & $\mathrm{EC}, \mathrm{CS}$ \\
\hline Zhen et al. (2019) & $\checkmark$ & & $\checkmark$ & & & & & $\checkmark$ & & $\checkmark$ & $\checkmark$ & $\checkmark$ & $\checkmark$ & & $\checkmark$ & & & & & SP & LR, CS \\
\hline Yavari and Zaker (2019) & $\checkmark$ & & $\checkmark$ & $\checkmark$ & & & & $\checkmark$ & & $\checkmark$ & & $\checkmark$ & $\checkmark$ & & $\checkmark$ & & & & $\checkmark$ & SP & CS, Oth \\
\hline Sabouhi et al. (2020) & $\checkmark$ & & & $\checkmark$ & $\checkmark$ & & $\checkmark$ & & & & & & $\checkmark$ & $\checkmark$ & $\checkmark$ & $\checkmark$ & & & & SP & BD, CS, Oth \\
\hline Vali-Siar and Roghanain (2020) & $\checkmark$ & $\checkmark$ & & $\checkmark$ & & & & & $\checkmark$ & & & & $\checkmark$ & $\checkmark$ & $\checkmark$ & $\checkmark$ & $\checkmark$ & & & $\mathrm{SP}, \mathrm{RO}$ & LR, CS \\
\hline Boronoos et al. (2021) & $\checkmark$ & & $\checkmark$ & & & & & $\checkmark$ & & $\checkmark$ & $\checkmark$ & $\checkmark$ & $\checkmark$ & & $\checkmark$ & $\checkmark$ & & & $\checkmark$ & PP & $\mathrm{CS}$, Oth \\
\hline Gholami-Zanjani et al. (2021a) & $\checkmark$ & & & $\checkmark$ & & & $\checkmark$ & & & & & & $\checkmark$ & & $\checkmark$ & $\checkmark$ & & & & SP & $\mathrm{BD}, \mathrm{CS}$ \\
\hline Gholami-Zanjani et al. (2021b) & $\checkmark$ & & & & & & $\checkmark$ & & & & & & $\checkmark$ & & $\checkmark$ & & & & & SP & Oth, CS \\
\hline Zare Mehrjerdi and Shafiee (2021) & $\checkmark$ & & & $\checkmark$ & & $\checkmark$ & & $\checkmark$ & & $\checkmark$ & $\checkmark$ & & $\checkmark$ & $\checkmark$ & $\checkmark$ & & & & $\checkmark$ & SP & $\mathrm{EC}, \mathrm{CS}$ \\
\hline Hasani et al. (2021) & $\checkmark$ & & $\checkmark$ & $\checkmark$ & & & $\checkmark$ & & & & & & $\checkmark$ & $\checkmark$ & $\checkmark$ & & & & $\checkmark$ & $\mathrm{SP}, \mathrm{RO}$ & MHeu \\
\hline Sabouhi et al. (2021) & $\checkmark$ & & & $\checkmark$ & & $\checkmark$ & $\checkmark$ & & & & & & $\checkmark$ & $\checkmark$ & $\checkmark$ & $\checkmark$ & & & $\checkmark$ & SP, RO & $\mathrm{BD}$ \\
\hline Sazvar et al. (2021) & $\checkmark$ & & & $\checkmark$ & & $\checkmark$ & $\checkmark$ & & & & & & $\checkmark$ & $\checkmark$ & $\checkmark$ & $\checkmark$ & & & & FRO & $\mathrm{GP}, \mathrm{CS}$ \\
\hline Fazli-Khalaf et al. (2021) & $\checkmark$ & & & $\checkmark$ & & $\checkmark$ & & $\checkmark$ & & $\checkmark$ & $\checkmark$ & $\checkmark$ & $\checkmark$ & & $\checkmark$ & & & & & PP & $\mathrm{CS}$ \\
\hline Zarrat Dakhely Parast et al. (2021) & $\checkmark$ & & $\checkmark$ & & & & & $\checkmark$ & & $\checkmark$ & $\checkmark$ & & $\checkmark$ & $\checkmark$ & $\checkmark$ & $\checkmark$ & & $\checkmark$ & $\checkmark$ & FP & $\mathrm{CS}$ \\
\hline Shabbir et al. (2021) & $\checkmark$ & & & $\checkmark$ & & $\checkmark$ & & $\checkmark$ & & $\checkmark$ & & $\checkmark$ & $\checkmark$ & $\checkmark$ & $\checkmark$ & $\checkmark$ & & & & SP, RO & $\mathrm{LR}, \mathrm{CS}$ \\
\hline This paper & $\checkmark$ & $\checkmark$ & $\checkmark$ & $\checkmark$ & $\checkmark$ & & & & $\checkmark$ & $\checkmark$ & $\checkmark$ & $\checkmark$ & $\checkmark$ & $\checkmark$ & $\checkmark$ & $\checkmark$ & $\checkmark$ & $\checkmark$ & $\checkmark$ & SP & MHeu, CS \\
\hline
\end{tabular}

This paper

selection (VS)// Uncertainty approach: Stochastic programming (SP), Robust optimization (RO), Fuzzy programming (FP), Fuzzy robust optimization (FRO)// Solution method: Heuristic (Heu),

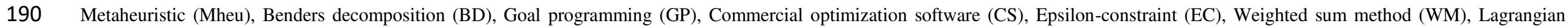




\section{Problem definition and mathematical modeling}

In this section the addressed problem is described and the developed mathematical model is presented.

\section{Problem definition}

In this paper a multi-echelon, and multi-period and multi-product supply chain network design/redesign problem is studied. The network structure is mixed open and closed-loop. The supply chain network consists of suppliers, production centers, distribution centers (DCs), customers, collection/inspection centers, recycling centers and remanufacturing centers. Production centers produce products using raw materials supplied by suppliers. These products can be transferred to distribution centers and from those centers to customer zones or sent directly from production centers to customer zones (two-channel distribution). The end-of-life (EOL) products are collected by collection centers and after inspection, a portion of returned products are transferred to recycling centers and a portion to remanufacturing centers. Also, a percentage of products that cannot be used for recycling or remanufacturing are transferred to disposal centers. In remanufacturing centers, products are converted into usable products of the same type as before, which have a relatively lower price and quality compared to main new products. These products are also sent to distribution centers and distribution centers send them to customer zones. In recycling centers, raw materials are extracted from recycled products and also recycled products used in other supply chains are produced. Extracted raw materials are sent to production centers to be utilized in producing new products and recycled products to other supply chains. There are different types of vehicles for transshipping products and materials. The establishment of facilities and different operations of supply chain have different costs and environmental impacts. It is assumed that there are various technologies for production centers, remanufacturing centers and recycling centers, each of which has a specific cost and environmental impact. the supply chain network studied in this paper is mixed open and closed-loop. Figure 1 schematically illustrates the supply chain under study.

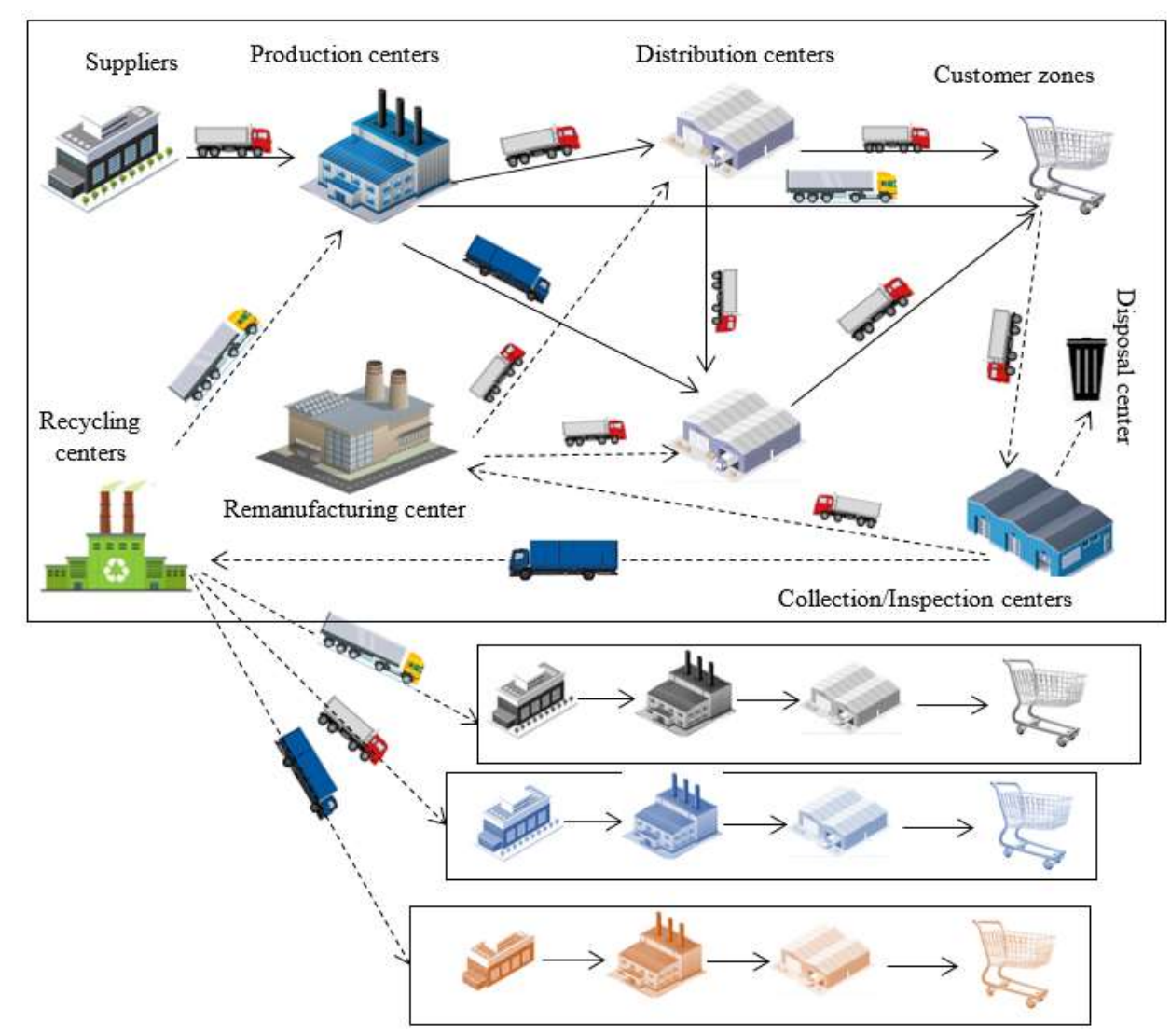

Fig. 1 The graphical representation of studied supply chain network

It is assumed that supply chain facilities and vehicles are exposed to disruptions. When disruption occurs for facilities, their capacity would be loosed partially or completely. Some resilient strategies are applied to cope with disruption risks and increase the resilience of the supply chain, including multiple sourcing, facility fortification, 
capacity expansion, dual-channel distribution (mentioned in the previous paragraph), dynamic pricing, lateral transshipment, and considering backup vehicles supplied by third-party logistics companies. Dynamic pricing can be utilized as a risk mitigation strategy. In dynamic pricing, different prices can be determined in each period for each product and each customer zone (Yavari et al., 2020). Given that the vehicles are exposed to disruptions, backup vehicles provided by third-party logistics companies are intended to help compensate for the lost capacity of the vehicles of the supply chain in the event of a disruption. Other strategies were explained in the last section. As mentioned in the introduction, disruptions can adversely affect the SC responsiveness. Hence, responsiveness should be considered in the SCND problem. In order to consider responsiveness, it can be included in the objective function or controlled by imposing constraints (Sabouhi et al., 2020). In this article, the second approach is used. In addition to the disruption risks, it is assumed that there is operational uncertainty in the production cost of main products and the cost of purchasing raw materials. All the mentioned uncertainties, whether of the disruption type or of the operational type, are scenario-based and are handled with the stochastic programming approach. The model decides on the establishment/closure of the facility, the flows between the facilities and the prices of the products.

We have assumed that the demands are price dependent, and there is a linear relationship between price and demand. The prices of products are discretized in order to avoid non-linearity. The modeling of the price-demand relationship is done similarly to the paper of Fattahi et al. (2018). For more details, interested readers are referred to the mentioned paper.

240

241

242

243

244

245

246

\section{Mathematical model}

In order to formulate the problem, a bi-objective mixed-integer linear programming model has been developed. The first objective is to maximize the total profit of the supply chain and the second one seeks to minimize the negative environmental impacts of the supply chain, including the greenhouse gas emissions and other destructive impacts originating from the establishment of facilities and other activities. At first, sets, parameters and variables are presented, and then the mathematical model is explained.

Sets

I Set of suppliers, indexed by $i$

Set of existing and potential production centers, indexed by $p$. The set of existing production

$P \quad$ centers is denoted by $P^{0}$, and the set of potential locations for production centers is denoted by $P^{n} . P=P^{n} \cup P^{0}$ and $P^{n} \cap P^{0}=\varphi$

$J \quad$ Set of existing and potential DCs, indexed by $j$ and $j^{\prime}$. The set of existing DCs is denoted by $J^{0}$, and the set of new potential locations for DCs is denoted by $J^{n} . P=J^{n} \cup J^{0}$ and $J^{n} \cap J^{0}=\varphi$

C Set of customers, indexed by $c$

$K \quad$ Set of potential locations for collection/ inspection centers, indexed by $k$

$H \quad$ Set of potential locations for recycling centers, indexed by $h$

$R \quad$ Set of potential locations for remanufacturing centers, indexed by $r$

$G \quad$ Set of supply chains, indexed by $g$

Set of vehicle types related to SC and third-party logistics company, indexed by $v$. The set of SC

$V \quad$ vehicle types is denoted by $V^{0}$, and the set of third-party logistics vehicle types is denoted by $V^{t p l} . V=V^{0} \cup V^{t p l}$.

A Set of fortification levels, indexed by $a$

$U_{1} \quad$ Set of production technologies, indexed by $u_{1}$

$U_{2} \quad$ Set of recycling technologies, indexed by $u_{2}$

$U_{3} \quad$ Set of remanufacturing technologies, indexed by $u_{3}$

$E \quad$ Set of product types, indexed by $e$

$O \quad$ Set of capacity levels for DCs and collection/inspection centers indexed by $o$

$l \quad$ Set of price levels, indexed by $l$

$T \quad$ Set of time periods, indexed by $t$

$S \quad$ Set of scenarios, indexed by $s$

247
Parameters
$f s_{i}$
$f p_{p u_{1} a}$
Fixed cost of selecting supplier $i$
Fixed cost of opening production

$f d_{j}$
$f c_{k}$
level $a$
$\quad$ Fixed cost of opening distribution center $j$
$c_{k} \quad$ Fixed cost of opening collection/ inspection center $k$ 


\begin{tabular}{|c|c|}
\hline$f l_{h u_{2} a}$ & $\begin{array}{l}\text { Fixed cost of opening recycling center } h \text { with recycling technology } u_{2} \text { and fortification level } \\
a\end{array}$ \\
\hline$f r_{r u_{3}} a$ & $\begin{array}{l}\text { Fixed cost of opening remanufacturing center } r \text { with remanufacturing technology } u_{3} \text { and } \\
\text { fortification level } a\end{array}$ \\
\hline $\mathrm{fcl}_{j}$ & Fixed cost of closing distribution center $j$ \\
\hline$f c d_{o j}$ & Fixed cost of developing capacity level $o$ for distribution center $j$ \\
\hline$f c c_{o k}$ & Fixed cost of developing capacity level $o$ for collection/inspection center $k$ \\
\hline$t c r_{v}$ & Unit transportation cost of raw and recycled materials using vehicle type $v$ per unit distance \\
\hline$t c p_{e v}$ & Unit transportation cost of product type $e$ using vehicle type $v$ per unit distance \\
\hline$\psi$ & Maximum number of existing distribution centers that can be closed \\
\hline$d a_{i p}$ & The distance between supplier $i$ and production center $p$ \\
\hline$d b_{p j}$ & The distance between production center $p$ and distribution center $j$ \\
\hline$d c_{p c}$ & The distance between production center $p$ and customer $c$ \\
\hline$d d_{j j \prime}$ & The distance between distribution centers $j$ and $j^{\prime}\left(j \neq j^{\prime}\right)$ \\
\hline$d e_{j c}$ & The distance between distribution center $j$ and customer $c$ \\
\hline$d f_{c k}$ & The distance between customer $c$ and collection/ inspection center $k$ \\
\hline$d g_{k r}$ & The distance between collection/ inspection center $k$ and remanufacturing center $r$ \\
\hline$d h_{k h}$ & The distance between collection/ inspection center $k$ and recycling center $h$ \\
\hline$d i_{r j}$ & The distance between remanufacturing center $r$ and distribution center $j$ \\
\hline$d j_{h p}$ & The distance between recycling center $h$ and production center $p$ \\
\hline$d k_{h g}$ & The distance between recycling center $h$ and production centers of supply chain $g$ \\
\hline$m c_{e p u_{1} s}$ & $\begin{array}{l}\text { Cost of producing one unit product type } e \text { in production center } p \text { with technology } u_{1} \text { under } \\
\text { scenario } s\end{array}$ \\
\hline$c e_{\text {peu }} s$ & $\begin{array}{l}\text { Cost per unit of adding extra production capacity for product type } e \text { in production center } p \\
\text { with technology } u_{1} \text { under scenario } s\end{array}$ \\
\hline$c d_{j}$ & Cost of distributing one unit of product in distribution center $j$ \\
\hline$c c_{k}$ & Cost of collecting and inspecting one unit of product in collection/ inspection center $k$ \\
\hline$r c_{h u_{2}}$ & Cost of recycling one unit of product in recycling center $h$ with technology $u_{2}$ \\
\hline$r m_{e r u_{3}}$ & $\begin{array}{l}\text { Cost of remanufacturing one unit of product type } e \text { in remanufacturing center } r \text { with } \\
\text { technology } u_{3}\end{array}$ \\
\hline$d p$ & Cost of disposing of one unit of product in disposal center \\
\hline$c r_{i s}$ & Cost of purchasing one unit of raw material from supplier $i$ under scenario $s$ \\
\hline$u d_{e c}$ & Cost of not meeting one unit of demand related to product type $e$ for customer $c$ \\
\hline$u d m_{e c}$ & $\begin{array}{l}\text { cost of not meeting one unit of demand related to remanufactured product type } e \text { for customer } \\
c\end{array}$ \\
\hline$u d r_{g}$ & Cost of not meeting one unit of demand related to recycled products for supply chain $g$ \\
\hline$e \mathrm{Pau}_{1}$ & $\begin{array}{l}\text { Environmental impact of establishing production center } p \text { with fortification level } a \text { and } \\
\text { manufacturing technology } u_{1}\end{array}$ \\
\hline$e o_{j}$ & Environmental impact of establishing distribution center $j$ \\
\hline$e o_{k}$ & Environmental impact of establishing collection/inspection center $k$ \\
\hline$e_{\mathrm{hau}_{2}}$ & $\begin{array}{l}\text { Environmental impact of establishing recycling center } h \text { with fortification level } a \text { and } \\
\text { manufacturing technology } u_{2}\end{array}$ \\
\hline$e_{\mathrm{rau}_{3}}$ & $\begin{array}{l}\text { Environmental impact of establishing remanufacturing center } r \text { with fortification level } a \text { and } \\
\text { manufacturing technology } u_{3}\end{array}$ \\
\hline$e p_{e p u_{1}}$ & $\begin{array}{l}\text { Environmental impact of producing a unit of product type } e \text { in production center } p \text { by using } \\
\text { manufacturing technology } u_{1}\end{array}$ \\
\hline$e d_{j}$ & Environmental impact of handling a unit of product in distribution center $j$ \\
\hline$e c_{k}$ & Environmental impact of handling a unit of product in collection/inspection center $k$ \\
\hline$e s_{e}$ & Environmental impact of disposing a unit of product type $e$ or releasing in environment \\
\hline$e l_{h u_{2}}$ & $\begin{array}{l}\text { Environmental impact of processing a unit of product in recycling center } h \text { by using } \\
\text { manufacturing technology } u_{2}\end{array}$ \\
\hline$e m_{e r u_{3}}$ & $\begin{array}{l}\text { Environmental impact of processing a unit of product type } e \text { in remanufacturing center } r \text { by } \\
\text { using manufacturing technology } u_{3}\end{array}$ \\
\hline$e t r_{v}$ & $\begin{array}{l}\text { Environmental impact of transporting a unit of raw material using vehicle type } v \text { per unit } \\
\text { distance }\end{array}$ \\
\hline
\end{tabular}




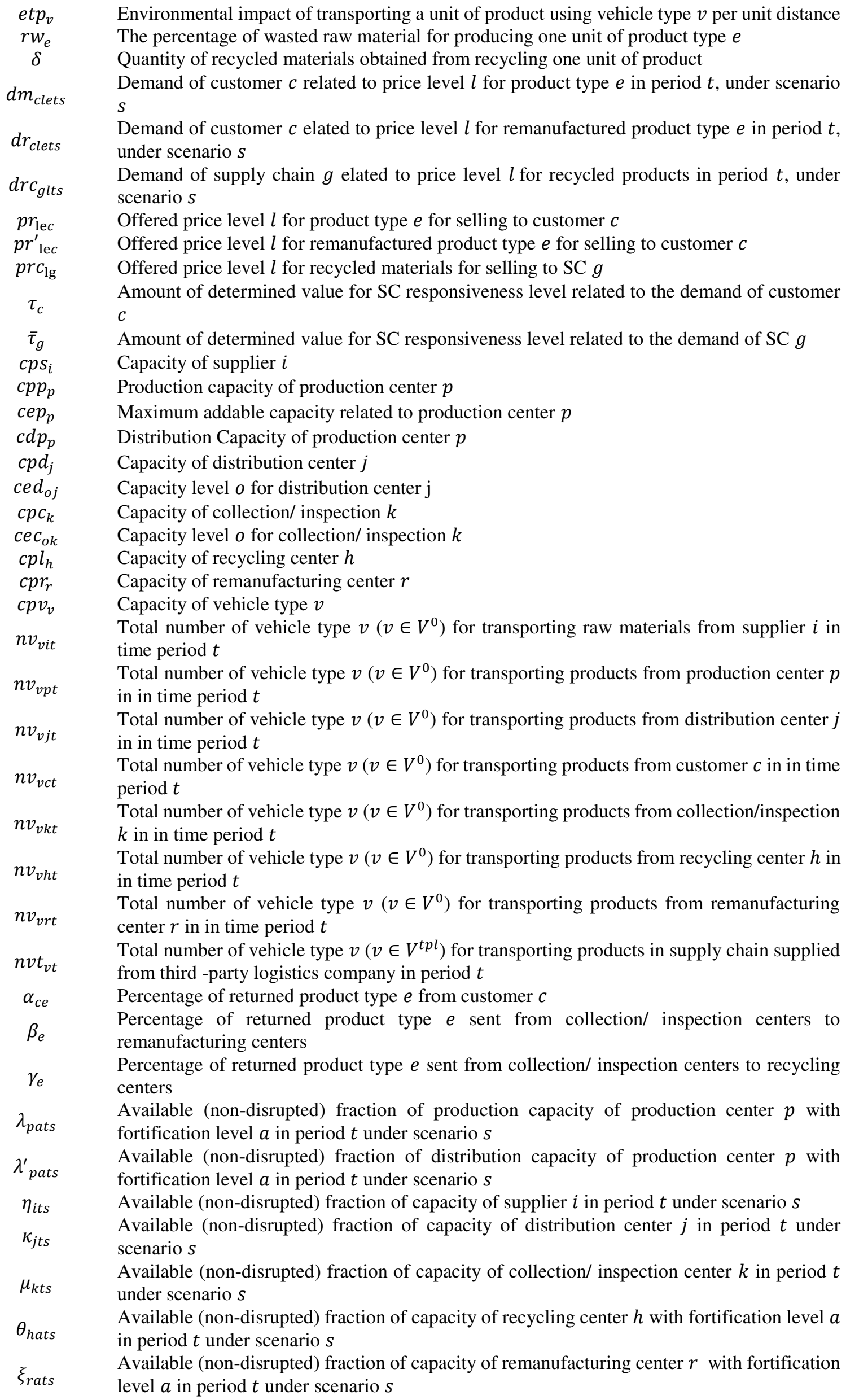


$\varphi 1_{v i t s} \quad$ Available (non-disrupted) fraction of total number of vehicle type $v\left(v \in V^{0}\right)$ for transporting raw materials from supplier $i$ in period $t$ under scenario $s$

$\varphi 2_{v p t s} \quad$ Available (non-disrupted) fraction of total number of vehicle type $v\left(v \in V^{0}\right)$ for transporting products from production center $p$ in period $t$ under scenario $s$

$\varphi 3_{v j t s} \quad$ Available (non-disrupted) fraction of total number of vehicle type $v\left(v \in V^{0}\right)$ for transporting products from distribution center $j$ in period $t$ under scenario $S$

$\varphi 4_{v c t s} \quad$ Available (non-disrupted) fraction of total number of vehicle type $v\left(v \in V^{0}\right)$ for transporting products from customer $c$ in period $t$ under scenario $s$

$\varphi 5_{v k t s} \quad$ Available (non-disrupted) fraction of total number of vehicle type $v\left(v \in V^{0}\right)$ for transporting products from collection/inspection $k$ in period $t$ under scenario $s$

$\varphi 6_{v h t s}$ Available (non-disrupted) fraction of total number of vehicle type $v\left(v \in V^{0}\right)$ for transporting products from recycling center $h$ in period $t$ under scenario $s$

$\varphi 7$ Available (non-disrupted) fraction of total number of vehicle type $v\left(v \in V^{0}\right)$ for transporting products from remanufacturing center $r$ in period $t$ under scenario $s$

$\pi_{s}$

Probability of scenario $s$ occurrence

Variables

$q r_{i p v t s}$

$m a_{e p u_{1} t s}$

$a c_{\text {peu }}$ ts

$q j_{\text {epjvts }}$

$q d_{\text {epcvts }}$

$q l_{e j j \prime v t s}$

Quantity of raw material shipped from supplier $i$ to production center $p$ using vehicle $v$ in period $t$ under scenario $s$

Quantity of product type $e$ produced at production center $p$ in period $t$ with technology $w$ under scenario $S$

Quantity of added capacity to production center $p$ for producing product type $e$ with technology $u_{1}$ in period $t$ under scenario $s$

Quantity of product type $e$ shipped from production center $p$ to distribution center $j$ using vehicle $v$ in period $t$ under scenario $s$

Quantity of product type $e$ shipped from production center $p$ to customer $c$ using vehicle $v$ in period $t$ under scenario $s$

Quantity of product type $e$ shipped from distribution center $j$ to distribution center $j^{\prime}$ using vehicle $v$ in period $t$ under scenario $s$

$q o_{e j c v t s}$

Quantity of product type $e$ shipped from distribution center $j$ to customer $c$ using vehicle $v$ in period $t$ under scenario $S$

qor $_{\text {ejcvts }}$

Quantity of remanufactured product type $e$ shipped from distribution center $j$ to customer $c$ using vehicle $v$ in period $t$ under scenario $s$

$q n_{\text {eckvts }}$

Quantity of product type $e$ shipped from customer $c$ to collection/ inspection center $k$ using vehicle $v$ in period $t$ under scenario $s$

$q f_{\text {ekvts }}$

Quantity of product type $e$ shipped from collection/ inspection center $k$ to remanufacturing center $r$ using vehicle $v$ in period $t$ under scenario $s$

$q b_{\text {ekhvts }}$

Quantity of product type $e$ shipped from collection/ inspection center $k$ to recycling center $h$ using vehicle $v$ in period $t$ under scenario $s$

Quantity of remanufactured product type $e$ remanufactured with technology $u_{3}$ shipped

$q m_{u_{3} \text { erjvts }}$ from remanufacturing center $r$ to distribution center $j$ using vehicle $v$ in period $t$ under scenario $S$

$f_{u_{2} h p v t s} \quad$ Quantity of recycled materials recycled with technology $u_{2}$ shipped from recycling center $h$ to production center $p$ using vehicle $v$ in period $t$ under scenario $s$

$f^{\prime}{ }_{u_{2} h g v t s}$ Quantity of recycled materials produced with recycling technology $u_{2}$ shipped from recycling center $h$ to supply chain $g$ using vehicle $v$ in period $t$ under scenario $s$

Quantity of unmet demand of customer $c$ for product type $e$ with price level $l$ in period $t$

$\omega_{\text {celts }}$

$\omega_{\text {celts }}^{\prime}$

$\omega^{\prime \prime}$ glts under scenario $S$

Quantity of unmet demand of customer $c$ for remanufactured product type $e l$ in period $t$ under scenario $S$

Quantity of unmet demand of supply chain $g$ for recycled materials in period $t$ under scenario $S$

$s s_{i} \quad$ A binary variable; 1 if supplier $i$ is selected, 0 otherwise

$x_{p a u_{1}}$

A binary variable; 1 if production center $p$ with fortification level $a$ and technology $u_{1}$ is established, 0 otherwise.

$y_{j} \quad$ A binary variable; 1 if distribution center $j$ is established, 0 otherwise

$z_{k}$

$r h_{\mathrm{hau}_{2}}$

$r r_{r_{3}}$

A binary variable; 1 if collection/ inspection center $k$ is established, 0 otherwise

A binary variable; 1 if recycling center $h$ with fortification level $a$ and technology $u_{2}$ is established, 0 otherwise.

A binary variable; 1 if remanufacturing center $r$ with fortification level $a$ and technology $u_{3}$ 
is established, 0 otherwise.

$x c d_{o j} \quad$ A binary variable; 1 if capacity level $o$ is developed for DC $j, 0$ otherwise.

$x c c_{o k} \quad$ A binary variable; 1 if capacity level $o$ is developed for collection/inspection center $j, 0$ otherwise.

$v_{\text {lects }} \quad$ A binary variable; 1 if price level $l$ is selected for product $e$ for selling to customer $c$ in period $t$ under scenario $S$

$v^{\prime} \quad$ A binary variable; 1 if price level $l$ is selected for remanufactured product $e$ for selling to customer $c$ in period $t$ under scenario $s$

$v^{\prime \prime}{ }_{\text {lgts }}$ A binary variable; 1 if price level $l$ is selected for recycled materials for selling to SC $G$ in period $t$ under scenario $s$

$\operatorname{Max} Z_{E c}=Z_{1}^{R}-\left(Z_{1}^{F}+Z_{1}^{T}+Z_{1}^{V}\right)$

$$
\begin{aligned}
& Z_{1}^{R}=\sum_{s} \pi_{s}\left(\sum _ { l } \sum _ { t } \left(\sum_{e} \sum_{c}\left(v_{\text {lects }} d m_{\text {clets }} p r_{\text {lec }}+v_{\text {lects }}^{\prime} d r_{\text {clets }} p r_{\text {lec }}^{\prime}-\omega_{\text {celts }} p r_{\text {lec }}-\omega_{\text {celts }}^{\prime} p r^{\prime}{ }_{\text {lec }}\right)\right.\right. \\
& \left.\left.+\sum_{g}^{s}\left(v^{\prime \prime}{ }_{l g t s} d r c_{l g t s} \operatorname{prc}_{l g}-\omega^{\prime \prime}{ }_{g l t s} \operatorname{prc}_{l g}\right)\right)\right) \\
& Z_{1}^{F}=\sum_{p} \sum_{u_{1}} \sum_{a} f p_{p u_{1} a} x_{p a u_{1}}+\sum_{i} f s_{i} s s_{i}+\sum_{j \in J^{n}} f d_{j} y_{j}+\sum_{j \in J^{0}} f c l_{j}\left(y_{j}^{\prime}\right) \\
& +\sum_{k} f c_{k} z_{k}+\sum_{h} \sum_{u_{2}} \sum_{a} f l_{h u_{2} a} r h_{h a u_{2}}+\sum_{h} \sum_{u_{3}} \sum_{a} f r_{r u_{3} a} r r_{r a u_{3}} \\
& Z_{1}^{T}=\sum_{s} \pi_{s}\left(\sum_{i} \sum_{p} \sum_{v} \sum_{t} t c r_{v} q r_{i p v t s} d a_{i p}\right. \\
& +\sum_{p}^{s} \sum_{j} \sum_{v} \sum_{t}^{p} t c p_{e v} q j_{e p j v t s} d b_{p j} \\
& +\sum_{p} \sum_{c} \sum_{e} \sum_{v} \sum_{t} t c p_{e v} q d_{e p c v t s} d c_{p c} \\
& +\sum_{j} \sum_{j \neq \neq j} \sum_{e} \sum_{v} \sum_{t} t c p_{e v} q l_{e j j \prime v t s} d d_{j j \prime} \\
& +\sum_{j} \sum_{c} \sum_{e} \sum_{v} \sum_{t} t c p_{e v}\left(q o_{e j c v t s}+q_{o r} r_{e j c t s}\right) d e_{j c} \\
& +\sum_{c} \sum_{k} \sum_{e} \sum_{v} \sum_{t} t c p_{e v} q n_{e c k v t s} d f_{c k} \\
& +\sum_{k} \sum_{r} \sum_{e} \sum_{v} \sum_{t} t c p_{e v} q f_{e k r v t s} d g_{k r} \\
& +\sum_{k} \sum_{h} \sum_{e} \sum_{v} \sum_{t} t c p_{e v} q b_{e k h v t s} d h_{k h} \\
& +\sum_{r} \sum_{j} \sum_{e} \sum_{u_{3}} \sum_{v} \sum_{t} t c p_{e v} q m_{u_{3} e r j v t s} d i_{r j} \\
& +\sum_{h} \sum_{p} \sum_{u_{2}} \sum_{v} \sum_{t} t c r_{v} f_{u_{2} h p v t s} d j_{h p} \\
& \left.+\sum_{u_{2}} \sum_{h} \sum_{g} \sum_{v} \sum_{t} t c r_{v} f_{u_{2} h g v t s}^{\prime} d k_{h g}\right) \\
& Z_{1}^{V}=\sum_{s} \pi_{s}\left(\sum_{i} \sum_{p} \sum_{v} \sum_{t} c r_{i s} q r_{\text {ipvts }}+\sum_{p} \sum_{e} \sum_{u_{1}} \sum_{t} m c_{e p u_{1} s} m a_{e p u_{1} t s}\right. \\
& +\sum_{p}^{s} \sum_{e} \sum_{u_{1}}^{i} \sum_{t}^{p} c e_{p e u_{1} s} a c_{p e u_{1} t s}+\sum_{j}^{p} \sum_{c} \sum_{e}^{e} \sum_{v}^{u_{1}} \sum_{t} c d_{j}\left(q o_{e j c v t s}+\text { qor }_{\text {ejcvts }}\right) \\
& +\sum_{c}^{p} \sum_{k}^{e} \sum_{e}^{u_{1}} \sum_{v}^{t} \sum_{t} c c_{k} q n_{\text {eckvts }}
\end{aligned}
$$


$+\sum_{h} \sum_{u_{2}} \sum_{v} \sum_{t} r c_{h u_{2}}\left(\sum_{p} f_{u_{2} h p v t s}+\sum_{g}{f^{\prime}}_{u_{2} h g v t s}\right)$

$+\sum_{r} \sum_{j} \sum_{u_{3}} \sum_{e} \sum_{v} \sum_{t} r m_{\text {eru }} q m_{u_{3} \text { erjots }}$

$+d p \sum_{e} \sum_{k} \sum_{v} \sum_{t}\left(\sum_{c} q n_{\text {eckvts }}-\sum_{r} q f_{\text {ekrvts }}-\sum_{h} q b_{\text {ekhvts }}\right)$

$+\sum \sum^{e} \sum_{c}^{k} \sum_{c}^{v} u d_{e c} \omega_{\text {celts }}$

$\left.+\sum_{c}^{c} \sum_{e}^{e} \sum_{l}^{l} \sum_{t}^{t} u d m_{e c} \omega_{c e t s}^{\prime}+\sum_{g} \sum_{l} \sum_{t} u d r_{g} \omega_{g l t s}^{\prime \prime}\right)$

$$
\begin{aligned}
& \operatorname{Min} Z_{E n}=Z_{2}^{F}+Z_{2}^{V}+Z_{2}^{T} \\
& Z_{2}^{F}=\sum_{p} \sum_{a} \sum_{w} e o_{\text {pau }_{1}} x_{p a u_{1}}+\sum_{j} e o_{j} y_{j}+\sum_{k} e o_{k} Z_{k}+\sum_{h} \sum_{a} \sum_{u_{2}} e o_{\text {hau }_{2}} r h_{\text {hau }_{2}} \\
& +\sum_{r} \sum_{u_{3}} \sum_{a} e o_{\text {rau }_{3}} \mathrm{rr}_{\mathrm{hau}_{3}} \\
& Z_{2}^{V}=\sum_{s} \pi_{s}\left(\sum_{p} \sum_{e} \sum_{u_{1}} \sum_{t} e p_{e p u_{1}}\left(m a_{e p u_{1} t s}+a c_{p e u_{1} t s}\right)\right. \\
& +\sum_{j}^{s} \sum_{c} \sum_{e}^{p} \sum_{v}^{e} \sum_{t}^{u_{1}} e d_{j}\left(q o_{e j c v t s}+\text { qor }_{\text {ejcvts }}\right)+\sum_{c} \sum_{k} \sum_{e} \sum_{v} \sum_{t} e c_{k} q n_{\text {eckvts }} \\
& +\sum_{h} \sum_{u_{2}} \sum_{v} \sum_{t} e l_{h u_{2}}\left(\sum_{p} f_{u_{2} h p v p t s}+\sum_{g} f^{\prime}{ }_{u_{2} h g v t s}\right) \\
& \left.+\sum_{r} \sum_{j} \sum_{u_{3}} \sum_{e} \sum_{v} \sum_{t} e \operatorname{eru}_{3} q m_{u_{3} e r j v t s}\right) \\
& +\sum_{e} \sum_{k} \sum_{v} \sum_{t} e s_{e}\left(\sum_{c} q n_{\text {eckvts }}-\sum_{r} q f_{\text {ekrvts }}-\sum_{h} q b_{\text {ekhvts }}\right) \\
& Z_{2}^{T}=\sum_{s} \pi_{s}\left(\sum_{i} \sum_{p} \sum_{v} \sum_{t} e t r_{v} q r_{i p v t s} d a_{i p}\right. \\
& +\sum_{p} \sum_{j} \sum_{e} \sum_{v} \sum_{t} e t p_{v} q j_{e p j v t s} d b_{p j} \\
& +\sum_{p} \sum_{c} \sum_{e} \sum_{v} \sum_{t} e t p_{v} q d_{e p c v t s} d c_{p j} \\
& +\sum_{j} \sum_{j \neq \neq j} \sum_{e} \sum_{v} \sum_{t} e t p_{v} q l_{e j j r v t s} d d_{j j \prime} \\
& +\sum_{j} \sum_{c} \sum_{e} \sum_{v} \sum_{t} e t_{v}\left(q o_{e j c v t s}+\text { qor }_{e j c v t s}\right) d e_{j c} \\
& +\sum_{c} \sum_{k} \sum_{e} \sum_{v} \sum_{t} e t p_{v} q n_{\text {eckvts }} d f_{c k} \\
& +\sum_{k} \sum_{r} \sum_{e} \sum_{v} \sum_{t} e t p_{v} q f_{e k r v t s} d g_{k r} \\
& +\sum_{k} \sum_{h} \sum_{e} \sum_{v} \sum_{t} e t p_{v} q b_{e k v t s} d h_{k h} \\
& +\sum_{r} \sum_{j} \sum_{e} \sum_{v} \sum_{t} e t p_{v} q m_{u_{3} e r j v t s} d i_{r j} \\
& +\sum_{h} \sum_{p} \sum_{u_{2}} \sum_{v} \sum_{t} e t r_{v} f_{u_{2} h p v p t s} d j_{h p}
\end{aligned}
$$




$$
\left.+\sum_{h} \sum_{g} \sum_{v} \sum_{t} e t r_{v} f_{u_{2} h g v t s} d k_{h g}\right)
$$

The first objective function (1) seeks to maximize supply chain profits. Supply chain profit is the sum of supply chain revenues minus supply chain costs. Supply chain revenue is calculated in Equation (1-1) and includes revenues from sales of major products, remanufactured products, and recycled products. Supply chain costs are shown in three sections. Fixed costs are calculated by Equation (1-2) and include the establishment/ closure costs of facilities and supplier selection. Equation (1-3) presents variable costs include the cost of producing products, purchasing raw materials, remanufacturing, disposal, recycling and costs of unmet demands. Transportation costs are also presented in Equation (1-4).

The second objective function minimizes the negative environmental impacts of the supply chain. The environmental impacts of establishing facilities are presented in Equation (2-1). Equation (2-2) calculates the environmental impacts of producing products, remanufacturing, recycling, and disposing of used products or releasing them into the environment. The environmental impacts of transportation are also considered in Equation $(2-3)$.

$$
\begin{array}{ll}
\sum_{a} \sum_{u_{1}} x_{\text {pau }_{1}} \leq 1 & \forall p \in p^{n} \\
\sum_{a} \sum_{u_{1}} x_{\text {pau }_{1}}=1 & \forall p \in p^{0} \\
\sum_{a} \sum_{u_{2}} r h_{\text {hau }_{2}} \leq 1 & \forall h \\
\sum_{a} \sum_{u_{3}} r r_{\text {rau }_{3}} \leq 1 & \forall r
\end{array}
$$

Constraints(3), (5) and (6) state that at most one fortification level and one technology should be selected for production centers, recycling centers and remanufacturing centers, respectively that are to be established. Constraint (4) is related to existing production centers that should be remained open.

$$
\begin{aligned}
& y_{j}^{\prime}=1-y_{j} \quad \forall j \in j^{0} \\
& \sum_{j \in j^{0}} y_{j}^{\prime} \leq \psi
\end{aligned}
$$

Constraint (7) computes the variable $y_{j}^{\prime}$ which is used in the first objective function. Constraint (8) limits the number of distribution centers that are to be closed.

$$
\sum_{i} \sum_{v} q r_{i p v t s}+\sum_{h} \sum_{u_{2}} \sum_{v} f_{u_{2} h p v t s}=\sum_{e}\left(1-r m_{e}\right) \sum_{u_{1}}\left(m a_{e p u_{1} t s}+a c_{p e u_{1} t s}\right) \quad \forall p, t, s
$$

Constraint (9) states that the raw materials required for manufacturing products are supplied by suppliers and recycling centers.

$$
\begin{aligned}
& \sum_{u_{1}}\left(m a_{e p u_{1} t s}+a c_{p e u_{1} t s}\right)-\sum_{c} \sum_{v} q d_{\text {epcvts }}=\sum_{j} \sum_{v} q j_{\text {epjvts }}+i v_{\text {epts }} \quad \forall p, e, t, s \\
& \sum_{p} \sum_{v} q j_{\text {epjvts }}+\sum_{j \neq \neq j} \sum_{v} q l_{e j j^{\prime} j t s}=\sum_{j \neq \neq j} \sum_{v} q l_{e j j \prime v t s}+\sum_{c} \sum_{v} q o_{e j c v t s} \quad \forall j, e, t, s \\
& \sum_{j} \sum_{v} q o_{e j c v t s}+\sum_{p} \sum_{v} q d_{e p c v 1 s}+\sum_{l} \omega_{\text {celts }}=\sum_{l} d m_{\text {clets }} v_{\text {lects }} \quad \forall e, c, t, s
\end{aligned}
$$

273 Constraints (10)-(12) guarantees balance of forward flows of the supply chain network. The mechanism of 274 transportation of products was described in the previous paragraphs of this section.

$$
\begin{aligned}
& \sum_{l} v_{\text {lects }}=1 \quad \forall c, e, t, s \\
& \sum_{l} v_{\text {lects }}^{\prime}=1 \quad \forall c, e, t, s
\end{aligned}
$$


$\sum_{l} v^{\prime \prime}{ }_{l g t s}=1 \quad \forall g, t, s$

275 Constraints (13)-(15) ensure that for each product under each scenario and in each period only one price level

276 should be selected.

$$
\begin{array}{ll}
\omega_{\text {celts }} \leq d m_{\text {clets }} v_{\text {lects }} & \forall c, e, l, t, s \\
\omega_{\text {celts }}^{\prime} \leq d r_{\text {clets }} v_{\text {lects }}^{\prime} & \forall c, e, l, t, s \\
\omega^{\prime \prime}{ }_{\text {glts }} \leq d r c_{\text {glts }} v^{\prime \prime}{ }_{\text {lgts }} & \forall g, l, t, s
\end{array}
$$

277 Constraints (16)-(18) guarantee that the amount of unmet demand should be less than or equal to the demand 278 corresponding to the selected price level.

$$
\begin{aligned}
& \sum_{k} \sum_{v} q n_{\text {eckvts }} \leq \alpha_{c e}\left(\sum_{j} \sum_{v} q o_{e j c v t s}+\sum_{p} \sum_{v} q d_{\text {epcvts }}\right) \quad \forall e, c, t, s \\
& \sum_{r} \sum_{v} q f_{e k r v t s} \leq \beta_{e} \sum_{c} \sum_{v} q n_{e c k v t s} \quad \forall e, k, t, s \\
& \sum_{h} \sum_{v} q b_{e k h v t s} \leq \gamma_{e} \sum_{c} \sum_{v} q n_{\text {eckvts }} \quad \forall e, k, t, s \\
& \sum_{u_{3}} \sum_{j} \sum_{v} q m_{u_{3} \text { erjvts }}=\sum_{k} \sum_{v} q f_{\text {ekrvts }} \quad \forall e, r, t, s \\
& \sum_{c} \sum_{v} \text { qor }_{\text {ejcvts }}=\sum_{u_{3}} \sum_{r} \sum_{v} q m_{u_{3} \text { erjots }} \quad \forall e, j, t, s \\
& \sum_{u_{2}} \sum_{p} \sum_{v} f_{u_{2} h p v p t s}+\sum_{u_{2}} \sum_{g} \sum_{v} f^{\prime}{ }_{u_{2} h g v t s}=\delta \sum_{e} \sum_{k} \sum_{v} q b_{\text {ekhvts }} \quad \forall h, t, s \\
& \sum_{j} \sum_{v} q \operatorname{rr}_{\text {ejcvts }}+\sum_{l} \omega_{\text {celts }}^{\prime}=\sum_{l} d r_{\text {clets }} v_{\text {lects }}^{\prime} \quad \forall c, e, t, s \\
& \sum_{h} \sum_{u_{2}} \sum_{v} f^{\prime}{ }_{u_{2} h g v t s}+\sum_{l} \omega^{\prime \prime}{ }_{g l t s}=\sum_{l} d r c_{g l t s} v^{\prime \prime}{ }_{\text {lgts }} \quad \forall g, t, s
\end{aligned}
$$

279 Constraints (19-26) ensures the balance of reverse flows of the supply chain based on the descriptions stated 280 before.

$$
\begin{aligned}
& \sum_{p} \sum_{v} q r_{i p v t s} \leq \eta_{i t s} c p s_{i} s s_{i} \quad \forall i, t, s \\
& \sum_{e} m a_{e p u_{1} t s} \leq c p p_{p} \sum_{a} \lambda_{p a t s} x_{p a u_{1}} \quad \forall p, t, u_{1}, s \\
& \sum_{e} \sum_{c} \sum_{v} q d_{e p c v t s} \leq c d p_{p} \sum_{a} \sum_{u_{1}} \lambda^{\prime}{ }_{p a t s} x_{p a u_{1}} \quad \forall p, t, s \\
& \sum_{e} a c_{p e u_{1} t s} \leq \operatorname{cep}_{p} \sum_{a} x_{p a u_{1}} \quad \forall p, t, u_{1}, s \\
& \sum_{o}^{e} x c d_{o j} \leq y_{j} \quad \forall j \\
& \sum_{o} x c c_{o k} \leq z_{k} \quad \forall j \\
& \sum_{c}^{o} \sum_{e} \sum_{v}\left(q o_{e j c v t s} q_{o r} r_{e j c v t s}\right) \leq \kappa_{j t s}\left(c p d_{j} y_{j}+\sum_{o} c e d_{o j} x c d_{o j}\right) \quad \forall j, t, s \\
& \sum_{c} \sum_{e} \sum_{v} q n_{e c k v t s} \leq \mu_{k t s}\left(c p c_{k} z_{k}+\sum_{o} c e c_{o k} x c c_{o k}\right) \quad \forall k, t, s \\
& \sum_{p} \sum_{v} f_{u_{2} h p v t s}+\sum_{g} \sum_{v} f^{\prime}{ }_{u_{2} h g v t s} \leq c p l_{h} \sum_{a} \theta_{h a t s} r h_{h a u_{2}} \quad \forall h, t, u_{2}, s \\
& \sum_{e} \sum_{j} \sum_{w_{9}} \sum_{v} q m_{u_{3} \text { erjots }} \leq \sum_{a} \xi_{r a t s} c p r_{r} r r_{r a u_{3}} \quad \forall r, t, u_{3}, s
\end{aligned}
$$


Constraints (27-36) assures that the maximum capacity limit of facilities is not violated. The effects of disruptions are considered in these constraints. Constraints (32) and (33) state that at most one capacity level can be selected for developing capacity of each distribution center and each collection center respectively.

$$
\begin{aligned}
& \sum_{p} q r_{\text {ipvts }} \leq \varphi 1_{v i t s} c p v_{v} n v_{v i t} \quad \forall i, v \in v^{0}, t, s \\
& \sum_{e} \sum_{j} q j_{\text {epjots }}+\sum_{e} \sum_{c} q d_{\text {epcvts }} \leq \varphi 2_{v p t s} c p v_{v} n v_{v p t} \forall p, v \in v^{0}, t, s \\
& \sum_{e} \sum_{j^{\prime}} q l_{e j j r v t s}+\sum_{e} \sum_{c}\left(q o_{e j c v t s}+q o r_{e j c v t s}\right) \leq \varphi 3_{v j t s} c p v_{v} n v_{v j t} \forall j, v \in v^{0}, t, s \\
& \sum_{e} \sum_{k} q n_{e c k v t s} \leq \varphi 4_{v c t s} c p v_{v} n v_{v c t} \quad \forall c, v \in v^{0}, t, s \\
& \sum_{e} \sum_{r} q f_{\text {ekrvts }}+\sum_{e} \sum_{h} q f_{\text {ekhvts }} \leq \varphi 5_{v k t s} c p v_{v} n v_{v k t} \forall k, v \in v^{0}, t, s \\
& \sum_{u_{3}} \sum_{e} \sum_{j} q m_{u_{3} \text { erjvts }} \leq \varphi 7_{v r t s} c p v_{v} n v_{v r t} \quad \forall r, v \in v^{0}, t, s \\
& \sum_{u_{2}} \sum_{p} f_{u_{2} h p v t s}+\sum_{u_{2}} \sum_{g} f_{u_{2} h g v t s}^{\prime} \leq \varphi 6_{v h t s} c p v_{v} n v_{v h t} \quad \forall h, v \in v^{0}, t, s \\
& \sum_{i} \sum_{p} q r_{\text {ipvts }}+\sum_{e} \sum_{p} \sum_{j} q j_{\text {epjvts }}+\sum_{e} \sum_{p} \sum_{c} q d_{\text {epcvts }} \\
& +\sum_{e} \sum_{j} \sum_{j^{\prime}} q l_{e j j \mathrm{j} t s}+\sum_{e} \sum_{j} \sum_{c}\left(q o_{e j c v t s}+\text { qor }_{e j c v t s}\right) \\
& +\sum_{e} \sum_{c} \sum_{k} q n_{e c k v t s}+\sum_{e} \sum_{k} \sum_{r} q f_{e k r v t s} \\
& +\sum_{e}^{e} \sum_{k}^{c} \sum_{h}^{k} q f_{\text {ekhvts }}+\sum_{u_{3}}^{e} \sum_{e}^{k} \sum_{r}^{r} \sum_{j} q m_{u_{3} \text { erjvts }} \\
& +\sum_{u_{2}} \sum_{h} \sum_{p} f_{u_{2} h p v t s}+\sum_{u_{2}} \sum_{h} \sum_{g} f^{\prime} u_{2} h g v t s \leq c p v_{v} n v t_{v t} \quad \forall v \in v^{t p l}, t, s
\end{aligned}
$$

Constraints (37) to (44) indicate the limitation on the capacity of supply chain vehicles. The capacity limit related to third-party logistics company is assured by constraint (46).

$$
\begin{aligned}
& \frac{\sum_{j} \sum_{e} \sum_{v} q o_{e j c v t s}+\sum_{e} \sum_{p} \sum_{v} q d_{\text {epcvts }}}{\sum_{e} \sum_{l} d_{\text {clets }} v_{\text {lects }}} \geq \tau_{c} \quad \forall c, t, s \\
& \frac{\sum_{e} \sum_{j} \sum_{v} q o r_{\text {ejcvts }}}{\sum_{e} \sum_{l} d r_{\text {clets }} v_{\text {lects }}^{\prime}} \geq \tau_{c} \quad \forall c, t, s \\
& \frac{\sum_{h} \sum_{u_{2}} \sum_{v} f^{\prime}{ }_{u_{2} \text { hgvts }}}{\sum_{l} d r c_{\text {glts }} v^{\prime \prime}{ }_{\text {lgts }}} \geq \bar{\tau}_{g} \quad \forall g, t, s
\end{aligned}
$$
fraction of satisfied demands.

$$
\begin{aligned}
& q r_{\text {ipvts }}, m a_{e p u_{1} 1 s}, a c_{\text {peu }} t s, i v_{e p t s}, q j_{\text {epjvts }}, q d_{\text {epcvts }}, q l_{\text {ejj,vts }}, q o_{\text {ejcvts }}, \\
& \text { qor }_{\text {ejcvts }}, q n_{\text {eckvts }}, q f_{\text {ekrvts }}, q b_{\text {ekhvts }}, q m_{u_{3} \text { erjvts }}, f_{u_{2} h p v p t s} \text {, } \\
& f^{\prime}{ }_{u_{2} \text { hgvts }}, \omega_{\text {celts }}, \omega_{\text {celts }}^{\prime}, \omega^{\prime \prime}{ }_{\text {glts }} \geq 0 \\
& s s_{i}, x_{\text {pau }_{1}}, y_{i}, z_{k}, r h_{\text {hau }_{2}}, r r_{\text {rau }_{3}}, x c d_{o j}, x c c_{o k}, v_{\text {lects }}, v_{\text {lects }}^{\prime}, v^{\prime \prime}{ }_{\text {lgts }} \in\{0,1\}
\end{aligned}
$$
Constraint (48) determines the types of variables.

\section{Solution methods}

Supply chain network design problem is NP-hard (Govindan et al., 2016). On the other hand, the problem of closed-loop supply chain network design are often more complex than forward supply chain design problem and is NP-hard (Soleimani and Govindan, 2015). Furthermore, the problem presented in this paper has a more complex structure than the closed-loop supply chain network design problem. Therefore, exact optimization methods are not applicable for solving medium and large-sized problems. solutions, including improved hybrid genetic and particle swarm optimization algorithm (hybrid GA-PSO), 
improved hybrid genetic and simulated annealing ( hybrid GA-SA) a novel hybrid algorithm titled hybrid ant colony optimization and teaching and learning-based optimization algorithm (hybrid ACO-TLBO). The

\section{Encoding and Decoding}

There are different methods for representing and encoding the solutions, among which two main approaches can be mentioned, including the matrix representation approach (Michalewicz et al, 1991) and the priority-based representation approach (Gen et al, 2006). In this paper, our representation method is similar to priority-based representation. An example is provided to illustrate how solutions are represented. It is assumed that the number of suppliers, production centers, distribution centers, customer zones, collection centers, recycling centers, remanufacturing centers and other supply chains are 2, 2, 2, 3, 2, 2, 2 and 2, respectively. The number of time periods is three. Also, there are four types of vehicles $\left(V^{0}=\{1,2,3\}\right.$ and $\left.V^{t p l}=\{4\}\right)$. The chromosome includes two sub-chromosomes. The first sub-chromosome determines the sequence of transportation between different facilities and specifies the vehicles for transshipping materials and products. As shown in Figure 2, the first subchromosomes is divided into eight segments based on the flows represented in Figure 1. Values entered in this sector are random numbers between $(0,1)$. These values are then sorted for each sub-segment in ascending order to make the priority-based matrix. The sector related to vehicles is filled by random numbers in the interval [1, $|V|]$.

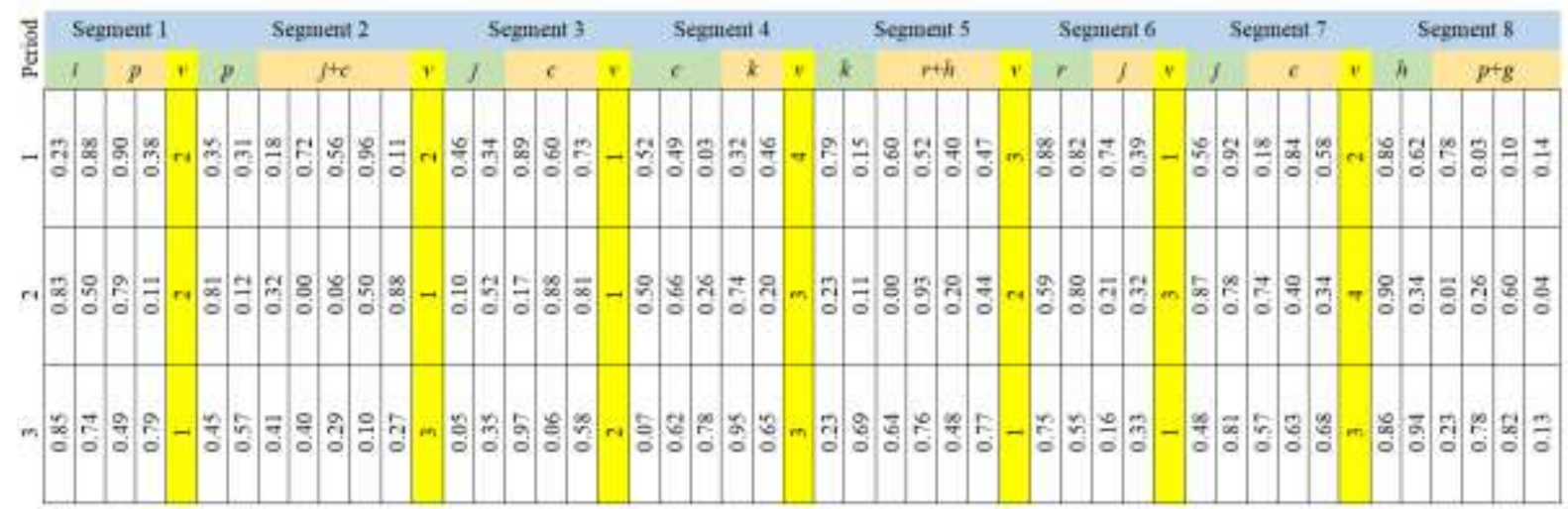

Fig. 2.a The graphical illustration the first sub-chromosome

\begin{tabular}{|c|c|c|c|}
\hline & & $e=1$ & $e=2$ \\
\hline \multirow{2}{*}{$t=1$} & $c=1$ & 1 & 4 \\
\cline { 2 - 4 } & $c=2$ & 4 & 2 \\
\hline \multirow{2}{*}{$t=2$} & $c=1$ & 3 & 1 \\
\cline { 2 - 4 } & $c=2$ & 5 & 2 \\
\hline
\end{tabular}

\begin{tabular}{|c|c|c|c|}
\hline & & $e=1$ & $e=2$ \\
\hline \multirow{2}{*}{$t=1$} & $c=1$ & 2 & 3 \\
\cline { 2 - 4 } & $c=2$ & 1 & 1 \\
\hline \multirow{2}{*}{$t=2$} & $c=1$ & 4 & 5 \\
\cline { 2 - 4 } & $c=2$ & 2 & 2 \\
\hline
\end{tabular}

\begin{tabular}{|l|l|l|}
\hline \multirow{2}{*}{$\mathrm{t}=1$} & $\mathrm{~g}=1$ & 1 \\
\cline { 2 - 3 } & $\mathrm{g}=2$ & 4 \\
\hline \multirow{2}{*}{$\mathrm{t}=2$} & $\mathrm{~g}=1$ & 3 \\
\cline { 2 - 3 } & $\mathrm{g}=2$ & 5 \\
\hline
\end{tabular}

Fig. 2.b The graphical illustration the second sub-chromosome

Fig. 2 The graphical illustration of proposed chromosome

In order to better explain the solution representation, segment 2 of the first sub-chromosome is explained in more detail. Figure 3 shows the priority based chromosome of this segment in period 1 . The second segment just like other segments, consists of two sub-segments. This segment is related to the transshipment of products from production centers $(p)$ to distribution centers $(j)$ and customers $(c)$. The first and second columns of sub-segment 2 are related to distribution centers the third to fifth columns are related to customer areas. The last column of this segment shows the selected type of vehicle for transporting product flows. As can be seen, the random values of chromosome are sorted independently for each sub-segment and the order of allocation is determined accordingly. For example, if production center 2 is established (according to the segment 1), products are initially shipped from this center to customer 1 , otherwise production center 2 is selected. Of course, it should be noted that constraints (7), (8), (10), (29), (31) and (33) should be considered in the described procedure. The values of variables related to product flows from production centers to distribution centers and customers and the binary variable corresponding to the establishment of distribution centers is determined based on this segment. In order to be 
concise, a pseudo-code is presented in Figure 4 which shows the general decoding procedure. For all segments, such a procedure should be implemented with differences in details and considering the related constraints.

The second sub-chromosome consists of three sectors. The first sector determines the price level of the main products and the second and third sectors determine the price level of the remanufactured and recycled products, respectively. The cells of each sector are filled with random numbers in interval $[1,|\mathrm{~L}|]$.

\begin{tabular}{|l|l|l|l|l|l|l|}
\multicolumn{1}{c}{$p$} & \multicolumn{5}{c|}{$j+c$} \\
\hline 2 & 1 & 2 & 4 & 3 & 5 & 1 \\
\hline
\end{tabular}

Fig. 3 The graphical illustration of priority based chromosome of segment 2 in period 1

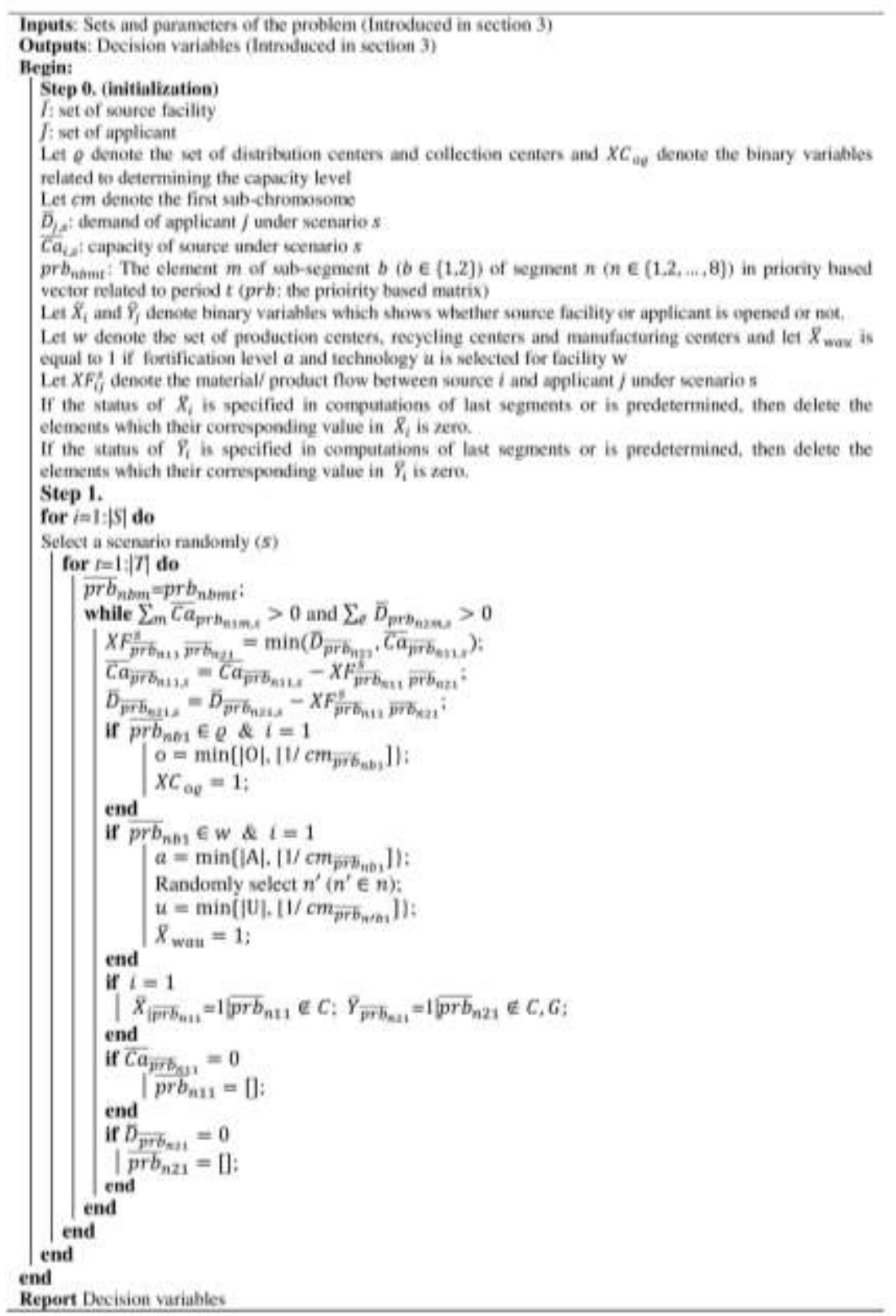

\section{Multi-objective hybrid ACO-TLBO}

Fig. 4 Pseudo-code of decoding procedure

Ant colony optimization was introduced by Dorigo (1992) and then further developed by Dorigo et al. (1996), Dorigo et al. (1999) and Dorigo and Stützle (2004). The ACO algorithm is inspired by the behavior of ants in nature for searching food. The ant searches for food around its colony, and when it finds food, picks it up and 
carries it to the nest. When it returns, it secretes a substance called pheromone which will be remained on the return way to help other ants in finding food. The amount of pheromone secreted depends on the quality and amount of food found (Socha and Dorigo, 2008). This method has been used as a combinatorial optimization tool in many studies, such as the supply chain design field, among which the works of Moncayo-Martínez and Zhang (2011) and Bottani et al. (2019) can be mentioned. Since the introduction of ACO, many attempts have been made to apply this algorithm in the continuous domain, but overall, these efforts were not successful, and the developed algorithms were only the inspirations of the ACO algorithm. Finally, Socha and Dorigo (2008) extended the ACO metaheuristic algorithm for continuous domains without any main changes used in the major concept of the ACO algorithm. The ACO metaheuristic for continuous domain (denoted by $\mathrm{ACO}_{\mathrm{R}}$ ) is useful for solving mixed discretecontinuous problems (Socha and Dorigo (2008) like the problem studied in this paper. In the following, we explain this algorithm based on the mentioned paper.

The first phase is Ant-Based Solution Construction. For implementing this algorithm at first $n_{\text {pop }}$ (archive size) random solutions $\left(s_{l}, l \in\left\{1, \ldots, n_{p o p}\right)\right)$ are generated by ants, and then evaluated and sorted based on their objective function values (from best to worst). The solutions and their related objective function values are stored in solution archive. Then, for each solution, a weight coefficient is computed which its related formula is expressed in the following.

To generate new solutions in the main loop of the algorithm, in contrast to the discrete ACO, a continuous probability distribution function (PDF) is used, which is made based on the solutions stored in the archive. At first, an ant should select one of the solutions (take a sample) from solution archive. This selection is done based on the probability of choosing solutions. For sampling and constructing new solutions, Socha and Dorigo (2008) suggested Gaussian function as a PDF. The PDF related to each dimension $i$ of the problem corresponding to solution $l$ is denoted by $g_{l}^{i}$. The Gaussian kernel as a weighted sum of one-dimensional Gaussian functions $g_{l}^{i}$ can be defined as follows:

$$
G^{i}(x)=\sum_{l=1}^{n_{\text {pop }}} p_{l} g_{l}^{i}(x)=p_{l} \frac{1}{\sigma_{i}^{l} \sqrt{2 \pi}} e^{-\frac{\left(x-s_{l}^{i}\right)}{2 \sigma_{i}^{l^{2}}}}
$$

Where $p_{l}$ is probability of selecting solution $l$ and is computed as follows:

$$
p_{l}=\frac{w_{l}}{\sum_{m=1}^{n_{p o p}} w_{m}}
$$

$w_{l}$ is the weight of solution $l$ and can be calculated by equation below:

$$
w_{l}=\frac{1}{q n_{p o p} \sqrt{2 \pi}} e^{-\frac{(l-1)}{2 q^{2} n_{p o p}^{2}}}
$$

Based on the above descriptions, the solution $s_{l}$ has rank $l . q$ is one of the parameters of the algorithm. With decreasing $q$, the preference of choosing the solution with better ranks increases. Equation (51) states that a higher value of a solution weight leads to higher probability of sampling around it. Sampling of the selected Gaussian function can be carried out utilizing a random number generator capable of generating random numbers according to a parameterized normal distribution (Socha and Dorigo, 2008).

The value of standard deviation $\sigma_{i}^{l}$ is calculated using the average distance of solution $s_{l}^{i}$ from other solutions of the archive.

$$
\sigma_{i}^{l}=\zeta \sum_{m=1}^{n_{p o p}} \frac{\left|s_{m}^{i}-s_{l}^{i}\right|}{n_{\text {pop }}-1}
$$

$\zeta$ is a positive parameter and has a similar effect compared to pheromone evaporation rate of ACO algorithm. The second phase of the ACOR algorithm is Pheromone Update. In this algorithm, the solution archive contains the pheromone information (Socha and Dorigo, 2008; Liao et al., 2013). Pheromone update is implemented by generating new solutions and adding them to the solution archive. After generating new solutions, they are merged in the archive, and the solutions should be sorted again. Note that during the implementation of the algorithm, the size of the archive should not be changed, and additional solutions with worse quality than other solutions must be removed. With increasing the quality of solutions stored in archive the guidance of ants in the search space will be done better. This process is iteratively done until the stopping criterion is met TLBO algorithm was introduced by Rao et al. (2011). It has been used in many studies in science and engineering and has proved its good performance for solving optimization problems (Rajesh, 2020). TLBO consists of two parts, including the teacher phase and the learner phase. TLBO is a population-based algorithm, so at first, $n_{p o p}$ 
solutions are randomly generated. The mission of the teacher phase is learning from a teacher. Let $s_{i, i t}$ denote the solution generated in iteration $i t$ related to solution $i$ and $M n_{i t}$ represent the mean of solutions of population in iteration $i t$. The teacher in iteration $i t$ is the best solution obtained until that iteration and is denoted by $T_{i t}$. The new solution sol $l_{i, i t}^{\text {new }}$ can be obtained as follows:

$$
\operatorname{sol}_{i, i t}^{\text {new }}=\operatorname{sol}_{i, i t}+r\left(T_{i t}-T F * M n_{i t}\right)
$$

Where $r$ is a random number in the range $[0,1]$ and $T F$ can be either 1 or 2 and is selected randomly. If the new solution is better than the old solution considering the fitness value, it will replace the old solution.

In the learner phase, the quality of learners (solutions) can be increased via interaction between themselves. In this phase in each iteration, for each solution $i$ a solution $j(i \neq j)$ is selected randomly. Then they should be compared based on their fitness values and the solution $i$ will be changed accordingly based on what is presented as follows:

$$
\begin{aligned}
& \text { If } \operatorname{sol}_{i, i t} \text { is better than } \operatorname{sol}_{j, i t} \\
& \qquad \operatorname{sol}_{i, i t}^{\text {new }}=\operatorname{sol}_{i, i t}+r\left(\operatorname{sol}_{i, i t}-\operatorname{sol}_{j, i t}\right) \\
& \text { else } \\
& \qquad \operatorname{sol}_{i, i t}^{\text {new }}=\operatorname{sol}_{i, i t}-r\left(\operatorname{sol}_{i, i t}-\operatorname{sol}_{j, i t}\right) \\
& \text { end }
\end{aligned}
$$

The new solution will replace the previous one if it has a better fitness value.

To the best of the authors' knowledge, the hybridization of $\mathrm{ACO}_{\mathrm{R}}$ and TLBO algorithm has not been studied before. To develop the structure of the hybrid algorithm, it should be noted that the problem studied in this paper is multi-objective, and an appropriate approach should be considered in designing the structure of the algorithm for handling this issue. Figure 5 represents the pseudo-code of the hybrid ACO-TLBO algorithm. At first, the solution archive is randomly populated, and solution weights and probability of selections are computed. Given that the problem is bi-objective, the non-dominated sorting algorithm (presented by Deb et al. 2002) is applied before the starting of the main loop. In the main loop of the algorithm, initially, the ACO steps are implemented and then the non-dominated sorting algorithm is applied. The first front obtained by this algorithm is selected as teachers and teaching operations are done. After that, the learning phase is fulfilled. Finally, after merging new solutions and the main population, non-dominated sorting is applied again. The best Pareto found solutions are reported after reaching the stopping criterion. 


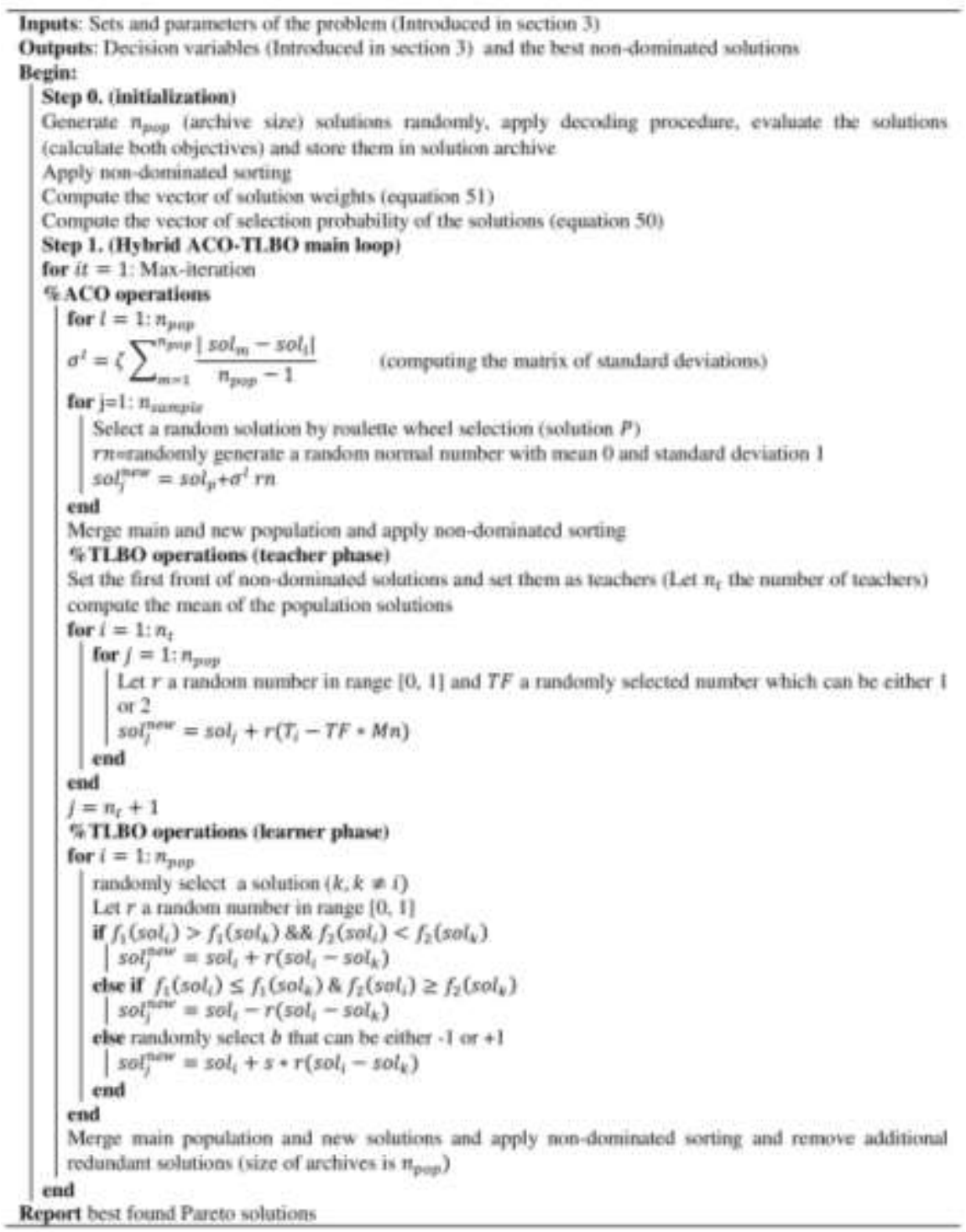

Fig. 5 Pseudo-code of multi-objective hybrid ACO-TLBO algorithm

In the multi-objective hybrid ACO-TLBO, the natural behavior of ants for searching food as well as the property of teaching and learning is observed in this algorithm. In fact, it can be said that ants searching for food in a space, help to improve the solutions by updating the pheromone (here by using the solution archive) utilize some teachers and learning interactions to further improve the solutions.

\section{Multi-objective hybrid improved GA-PSO}

Genetic algorithm was introduced by Holland (1975), and PSO was developed by Kennedy and Eberhart (1995). These two algorithms are well-known metaheuristics that have shown good performance in optimization problems of different fields. The hybridization of GA and PSO has been used in many research papers and has demonstrated very good results (Soleimani and Govindan, 2015). In this paper, we have proposed the multi-objective hybrid improved GA-PSO as another solution method. The non-dominated sorting approach presented by Deb et al. (2002) is utilized in the proposed hybrid algorithm to cope with multi-objectivity. The pseudo-code of the algorithm is presented in Figure 6.

In this algorithm, at first $n_{\text {pop }}$ number of solutions are randomly generated. In the next step, at first, GA operations are implemented. In implementing GA, two steps are added to the traditional framework. The first one is saving $n_{e}$ number of best solutions (elites) after implementing crossover. These solutions can replace dominated solutions generated by mutation operator to improve the quality of population and increase the speed of obtaining highquality Pareto set. The second step is the local search imbedded in the mutation operator. In this mutation, two 
and the solution is generated based on it. Three types of crossovers are used, including single-point, double point and uniform. After executing GA operators, the PSO operators are run and the process is iterated until the stopping criterions is reached.

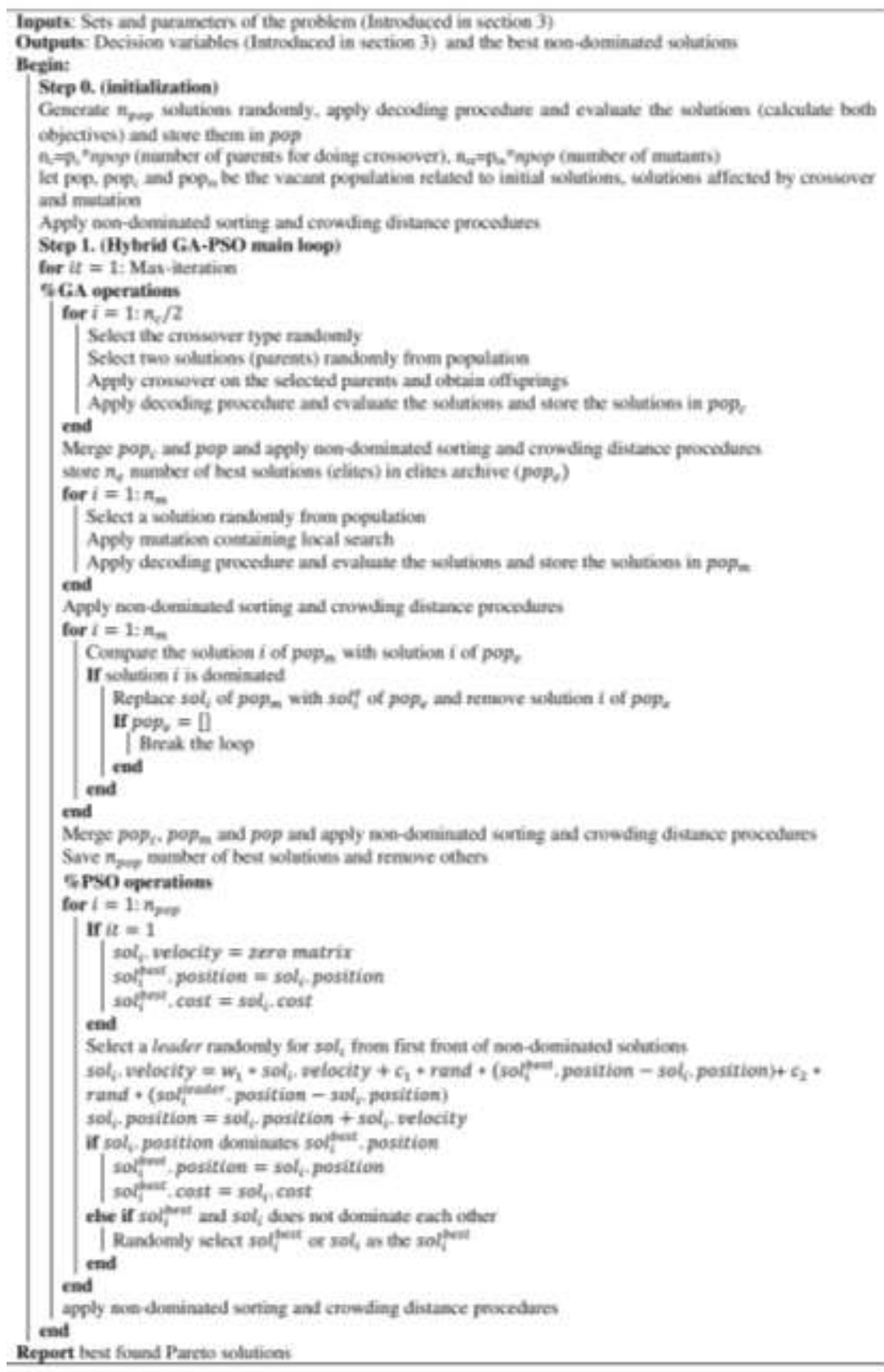

Fig. 6 Pseudo-code of multi-objective hybrid improved GA-PSO

\section{Multi-objective hybrid improved GA-SA}

Simulated annealing was introduced by Kirkpatrick (1983) in order to handle large-sized combinatorial optimization problems. In the proposed hybrid improve GA-SA, The GA operators are initially executed and then the SA commands are run. Three mutation operators are applied in SA including swap, insertion and reversion. The pseudo-code of hybrid improved GA-SA algorithm is shown in Figure 7. In the presented pseudo-code $\Delta f_{o}=$ $f_{o}\left(x^{\text {new }}\right)-f_{o}\left(x^{\text {old }}\right)$ were $\mathrm{x}$ is the solution and $o$ denotes the objective function. 


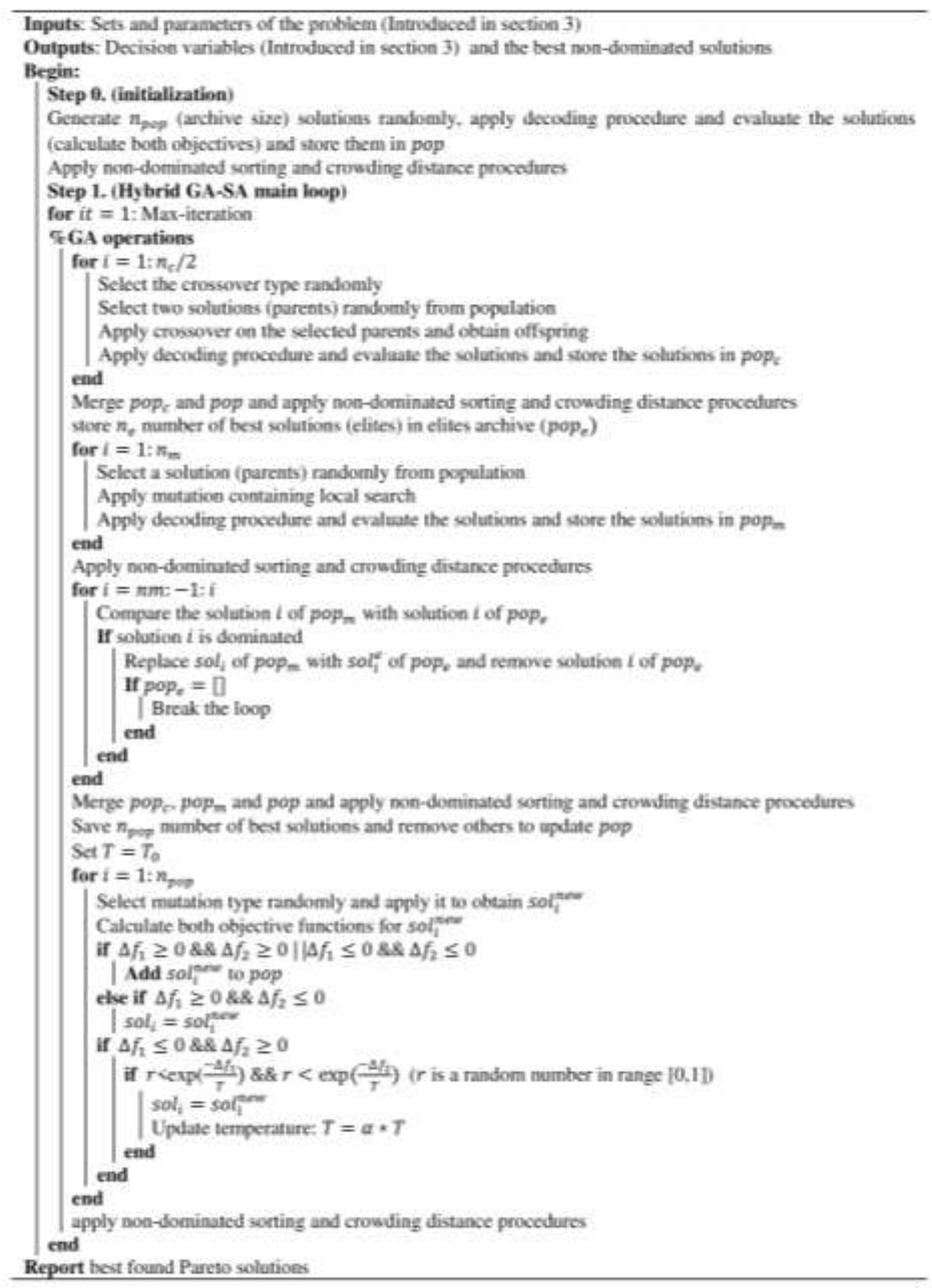

Fig. 7 Pseudo-code of hybrid multi-objective hybrid improved GA-SA

\section{Computational results and analyses}

In this section, at first, the ranges and values of the parameters of the problem are presented, and then the parameters of the proposed metaheuristic algorithms are tuned using the Taguchi method. The parameters setting of the model is done based on a real case study. After the parameter setting of the model and solution methods, the problem is solved via solution methods, and computational results and analyses are reported.

The mathematical model is coded in Gams optimization software version 24.1.3, and the metaheuristics are coded in MATLAB version 2015a. The problems are run on a computer with $16 \mathrm{~GB}$ of RAM and an Intel (R) Core (TM) i73720QM, 2.6 GHz CPU, running on Windows 10 (64-bit).

\section{Case study and test problems}

In this paper, a tire supply chain in Iran is presented as a real case study to show the applicability of the mathematical model and solution methods. The tire industry is a developing industry with recyclable products, where according to a forecast, the global market of this sector will register an annual growth of $3.8 \%$ until 2025 
environmental and health damages. The used tires can be remanufactured (retreaded) and sold in target markets at lower prices. Moreover, different materials can be recycled from scrap tires including steel, rubber powder, fiber and tire granulate which can be used for different applications. For example, tire granulate can be utilized in upper asphalt layer of roads. Also, the recycled materials like tire rubber can be applied for its original purpose which is producing new tires (Subulan et al., 2015). Figure 8 depicts the component of a tire. Figure 9 presents the materials and products obtained by recycling tires.

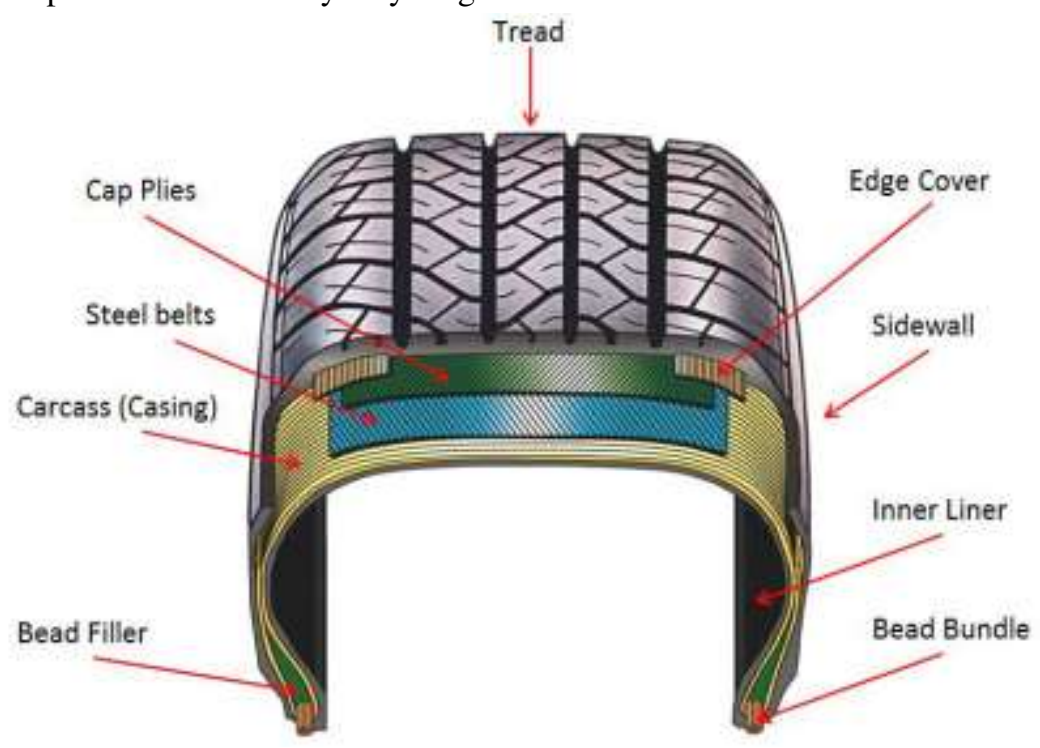

Fig.8 The structure of a tire (source: www.carbiketech.com/tyre)

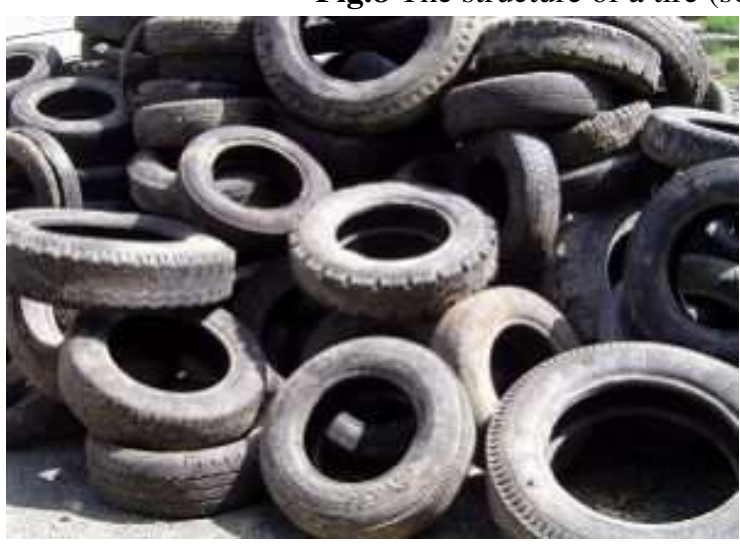

a Scarp tires (Lawson, 2018)

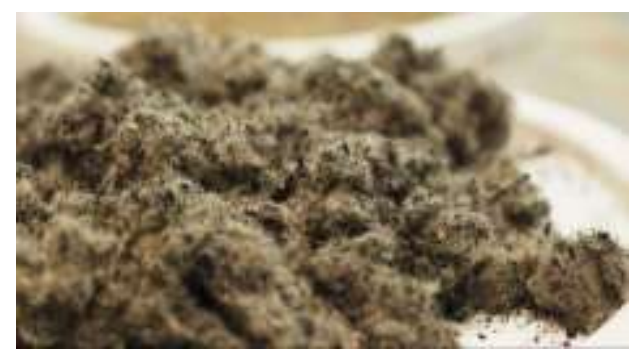

c Tire fiber (source: www.cdrecycler.com)

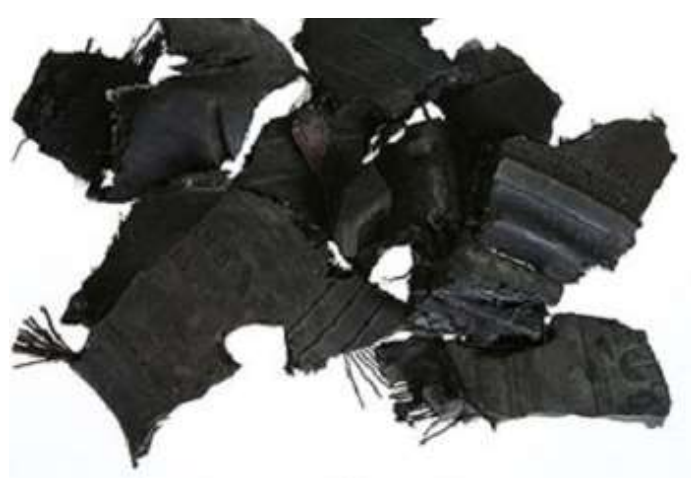

b tire chips (source: www.iran-lastic.ir)

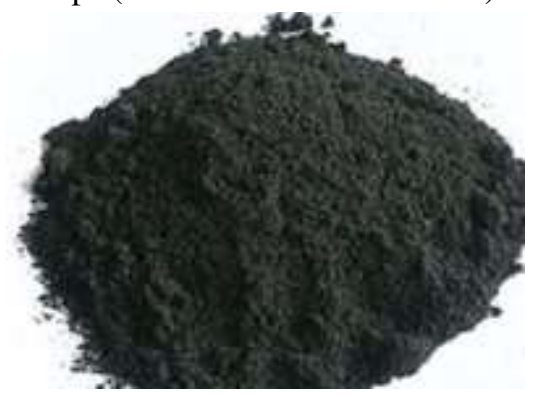

d rubber powder (source: www.iran-lastic.ir) 


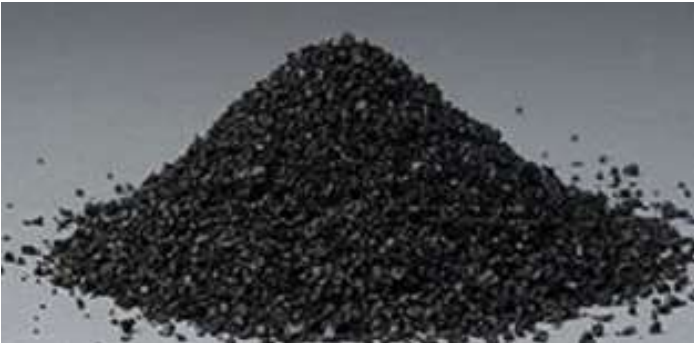

e tire granulate (source: www.iran-lastic.ir)

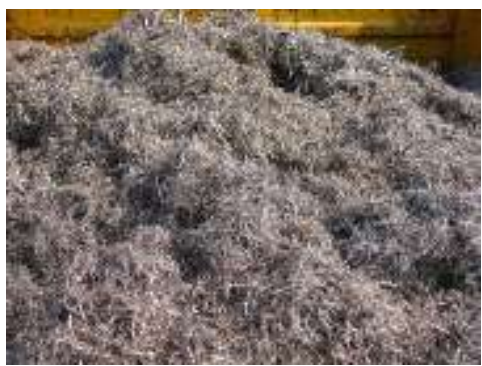

f tire steel (source: www.europeanrecycle.com)

Fig. 9 Scarp tires (a) and recycled products (b-f)

472

473

474

475

476

477

478

479

480

481

482

483

484

In order to evaluate the performance of the proposed solution methods and compare them, twelve test problems are randomly generated based on the data of the case study. The dimensions of the test problems and the case study is presented in Table 2. Scenarios shows different situations caused by disruptions. The intensity of disruptions are randomly generated using uniform distribution and the intervals presented in Table 3 . In all problems, the number of members of theses sets are same: The number of capacity levels of distribution centers and collection centers, 4 , the number of price levels, 5 and the number of fortification levels and technology types for all related facilities, 3 .

The SC considered for the case study currently consists of one factory, two distribution centers and four suppliers. The company is investigating the development and redesign of its supply chain to combat potential disruptions and increase network resilience. Also, in order to pay attention to environmental issues and create a green supply chain, the company seeks to develop reverse logistics and finally utilize a mixed supply chain network.

Table 2 Size of the case study and test problems

\begin{tabular}{|c|c|c|c|c|c|c|c|c|c|c|c|c|}
\hline $\begin{array}{c}\text { Problem } \\
\text { No. }\end{array}$ & $|I|$ & $|P|$ & $|E|$ & $|J|$ & $|C|$ & $|K|$ & $|H|$ & $|R|$ & $|G|$ & $|V|$ & $|T|$ & $|S|$ \\
\hline Case study & 4 & 2 & 4 & 4 & 7 & 2 & 2 & 2 & 6 & 4 & 4 & 6 \\
\hline 1 & 2 & 1 & 2 & 2 & 3 & 2 & 1 & 1 & 2 & 2 & 2 & 3 \\
\hline 2 & 3 & 2 & 2 & 3 & 4 & 3 & 2 & 2 & 2 & 2 & 2 & 3 \\
\hline 3 & 4 & 3 & 4 & 5 & 5 & 4 & 2 & 3 & 3 & 2 & 3 & 3 \\
\hline 4 & 5 & 4 & 6 & 6 & 7 & 10 & 4 & 4 & 4 & 2 & 3 & 3 \\
\hline 5 & 9 & 7 & 8 & 10 & 15 & 12 & 10 & 8 & 9 & 3 & 4 & 4 \\
\hline 6 & 11 & 8 & 8 & 13 & 18 & 14 & 12 & 10 & 11 & 3 & 4 & 5 \\
\hline 7 & 12 & 9 & 9 & 16 & 21 & 15 & 13 & 12 & 13 & 3 & 6 & 6 \\
\hline 8 & 14 & 12 & 10 & 18 & 26 & 17 & 15 & 14 & 15 & 3 & 6 & 7 \\
\hline 9 & 20 & 14 & 11 & 24 & 34 & 22 & 19 & 18 & 20 & 4 & 8 & 9 \\
\hline 10 & 22 & 16 & 11 & 27 & 40 & 24 & 21 & 19 & 22 & 4 & 8 & 10 \\
\hline 11 & 24 & 18 & 12 & 29 & 46 & 25 & 23 & 21 & 25 & 4 & 8 & 12 \\
\hline 12 & 28 & 20 & 12 & 30 & 50 & 27 & 24 & 22 & 27 & 4 & 8 & 12 \\
\hline
\end{tabular}

485

486

487

488

The ranges and values of parameters are given in Table 3. The unit of parameters related to prices and costs is Toman and are expressed in million Tomans. The unit of the parameters related to materials and products (demand and capacity) is Ton.

Table 3 Ranges of the model parameters

\begin{tabular}{cccc}
\hline Parameter & Range/ Value & Parameter & Range/ Value \\
\hline$f s_{i}$ & {$[6,12]$} & $\delta$ & {$[0.4,0.6]$} \\
$f p_{p u_{1} a}$ & {$[40000,200000]$} & $d m_{\text {clets }}$ & {$[300,800]$} \\
$f d_{j}, f c_{k}$ & {$[150,500]$} & $d r_{\text {clets }}$ & {$[100,300]$} \\
$f l_{h u_{2} a}, f r_{h u_{3} a}$ & {$[1000,4000]$} & $d r c_{g l t s}$ & {$[50,200]$} \\
$f c l_{j}$ & {$[100,300]$} & $c p s_{i}$ & {$[15000,25000]$} \\
$f c c_{o k} f c d_{o j}$ & {$[0.5,1]$} & $c p p_{p}$ & {$[5000,10000]$} \\
$t c r_{v}, t c p_{e v}$ & {$[0.004,0.008]$} & $c e p_{p}$ & {$[200,1000]$} \\
distance parameters & {$[100,2000](\mathrm{km})$} & $c e p_{j o}, c e c_{k}$ & {$[12500,25000]$} \\
$m c_{\text {epu }} s$ & {$[30,40]$} & $c h p_{p}$ & {$[1000,5000]$} \\
$c e_{p e u_{1} s}$ & {$[40,50]$} & $c p l_{h}$ & {$[5000,10000]$} \\
$c h_{e p}, c c_{k}, c d_{j}$ & {$[3,6]$} & $c d p_{p}$ & {$[3000,15000]$} \\
$r c_{h u_{2}}$ & {$[0.3,0.6]$} & $c p r_{r}$ & {$[4000,10000]$} \\
$r m_{e r u_{3}}$ & {$[5,10]$} & & {$[2000,10000]$}
\end{tabular}




\begin{tabular}{|c|c|c|c|}
\hline$d p$ & {$[0.0004,0.0006]$} & $c p v_{v}$ & {$[5,45]$} \\
\hline$c r_{i s}$ & {$[10,15]$} & $\begin{array}{l}\lambda_{\text {pats }}, \lambda_{\text {pats }}^{\prime}, \lambda_{\text {pats }}^{\prime \prime}, \eta_{\text {its }}, \\
\quad, \xi_{\text {rats }} \kappa_{\text {jts }}, \mu_{\text {kts }}, \theta_{\text {hats }}\end{array}$ & {$[0,1]$} \\
\hline$p r_{l e c}$ & {$[80,120]$} & $\begin{array}{c}\varphi_{v \alpha t s} \\
(\alpha \in i, p, j, c, k, h, r)\end{array}$ & {$[0,1]$} \\
\hline $\operatorname{prc}_{l g}$ & {$[2,5]$} & $\begin{array}{c}n v_{v t} \\
(\alpha \in i, p, j, c, k, h, r)\end{array}$ & {$[5,20]$} \\
\hline$u d_{e c}$ & {$[15,25]$} & $n v t_{v t}$ & {$[20,60]$} \\
\hline$\overline{u d} m_{e c}$ & {$[8,12]$} & $\alpha_{c e}$ & {$[0.25,0.95]$} \\
\hline$u d r_{g}$ & {$[1,4]$} & $\gamma_{e} \beta_{e}$ & {$[0.1,0.5]$} \\
\hline $\begin{array}{c}e o_{\text {pau }_{1}}, e o_{j}, e o_{k}, e o_{\text {hau }_{1}}, \\
e o_{\text {rau }_{3}}\end{array}$ & {$[1,10]$} & $\tau_{c s}, \bar{\tau}_{q s}$ & {$[0.4,0.9]$} \\
\hline $\begin{array}{c}, e p_{e p u_{1}}, e d_{j}, e c_{k}, e s_{e} \\
e l_{h u_{2}}, e m_{e r u_{3}} \\
e t r_{v}, e t p_{v}\end{array}$ & $\begin{array}{c}{[0.01,0.1]} \\
{[0.0001,0.1]}\end{array}$ & $r w_{e}$ & {$[0,0.15]$} \\
\hline
\end{tabular}

489

490

491

492

493

494

495

496

497

498

499

500

501

502

503

504

505

506

507

508

509

510

511

\section{Performance metrics}

Given that problem under study is multi-objective, it is not possible to assess the performance of the solution methods using a simple criterion; therefore, in this paper, some performance metrics are applied in order to measure and compare the performance of the presented multi-objective algorithms. These metrics have been used in many papers of the literature.

- Number of pareto solutions (NPS): This criterion shows the number of obtained Pareto undefeated points.

Achieving more Pareto solutions increases the quality and power of decision-making.

- Computational time (CPU time): This metric gives the time spent for obtaining non-dominated solutions by an algorithm. It is clear that lower CPU times are more desirable.

- Quality metric (QM): In order to calculate this metric, at first the non-dominated solutions obtained by all algorithms are stored in an archive, and then by comparing these solutions, the dominated ones are removed so that the archive contains only the dominated solutions. Finally, the ratio of the number of non-dominated solutions belonging to an algorithm to the total number of non-dominated solutions gives the quality metric for that algorithm. The higher this criterion, the higher the quality of the algorithm

- Mean ideal distance (MID): This metric evaluates the distance of obtained Pareto solutions from ideal point. Here, the ideal point denotes the situation that the first objective is at its maximum value $\left(f_{1}^{\text {best }}\right)$ and the second objective is at its minimum value $\left(f_{1}^{\text {best }}\right)$. The ideal point can be considered equal to the maximum value of the first objective function and the minimum value of the second objective function in all algorithms. This metric can be calculated by equation (55). In this equation, $f_{i, \text { total }}^{\max }$ and $f_{i, \text { total }}^{\min }$ represent the highest and lowest values of the objective functions among all obtained non-dominated solutions, respectively. $n$ denotes the number of Pareto solutions. The lower values of this criterion indicate the higher quality of the algorithm (Karimi et al., 2010).

$$
M I D=\frac{\sum_{i=1}^{n} \sqrt{\left(\frac{\left.f_{1 i-} f_{1}^{\text {best }}\right)}{f_{1, \text { total }}^{\text {max }}-f_{1, \text { total }}^{\text {min }}}\right)^{2}+\left(\frac{\left.f_{2 i-} f_{2}^{\text {best }}\right)}{f_{2, \text { total }}^{\text {max }}-f_{2, \text { total }}^{\text {min }}}\right)^{2}}}{n}
$$

- Spacing metric (SPM): This metric indicates that how evenly the non-dominated solutions are distributed along the obtained Pareto frontier and can be calculated as follows (Tan et al., 2006):

$S P M=\left[\frac{1}{n} \sum_{i=1}^{n}\left(d_{i}-\bar{d}\right)^{2}\right]^{1 / 2}$

In the above equation, $d_{i}$ is the Euclidean distance between solution $i$ and its nearest neighbor in the Pareto frontier. $\bar{d}=\sum_{i=1}^{n} d_{i} / n$. Where $n$ is the number of pareto solutions. Smaller values of SPM are desirable.

- Diversification metric (DM): As the name of this metric implies, it measures the diversity of non-dominated solutions found by an algorithm. Higher values of DM indicate better performance of algorithm (Maghsoudlou et al., 2016). This metric can be computed by equation (57).

$D M=\sqrt{\left(\max f_{1 i}-\min f_{1 i}\right)^{2}+\left(\max f_{2 i}-\min f_{2 i}\right)^{2}}$ 
In order to achieve the best performance of metaheuristics, in this section, the parameters of the metaheuristic algorithms are tuned using the Taguchi method. This method is utilized in order to avoid plenty number of experiments of full factorial experimental design. In this method, factors are classified into two categories: controllable and noise. The desired value is represented by signal and the undesirable value is denoted by noise. In the Taguchi method, the concept of signal to noise ratio $(\mathrm{S} / \mathrm{N})$, which represents the variation of response value, is used. Taguchi method attempts to reduce the effect of noise factors (Kumar, 2017). There are three types of responses, including "smaller is better", "nominal is best" and "larger is better" (Roy, 2010). In this article the "smaller is better" is applied for tuning the parameters of algorithms.

$$
S / N=-10 \log \left[\frac{1}{n} \sum_{i=1}^{n} y^{2}\right]
$$

529

530

531

532

533

534

535

536

537

538

In the above equation, $y$ represents the response value and $n$ denotes the number of orthogonal arrays. In order to tune the parameter of algorithms, at first, the level of parameters belonging to algorithms are determined. The levels of parameters are presented in Table 4. In this table, $\Psi=|I|+|P|+|J|+|C|+|K|+|R|+|H|+|G|$. The determined values are selected based on vast experiments and the related papers of the literature.

In the next step, a Taguchi design is created using Minitab software and finally the Taguchi design is analyzed to choose the best levels of parameters.

Using Taguchi method, the $L^{27}$ orthogonal arrays are proposed for tuning the parameters of algorithms. The $\mathrm{S} / \mathrm{N}$ diagrams are depicted in Figures 10-12. The test problem number 4 was selected for doing the experiments. The bold values in Table 4 show the proper levels selected.

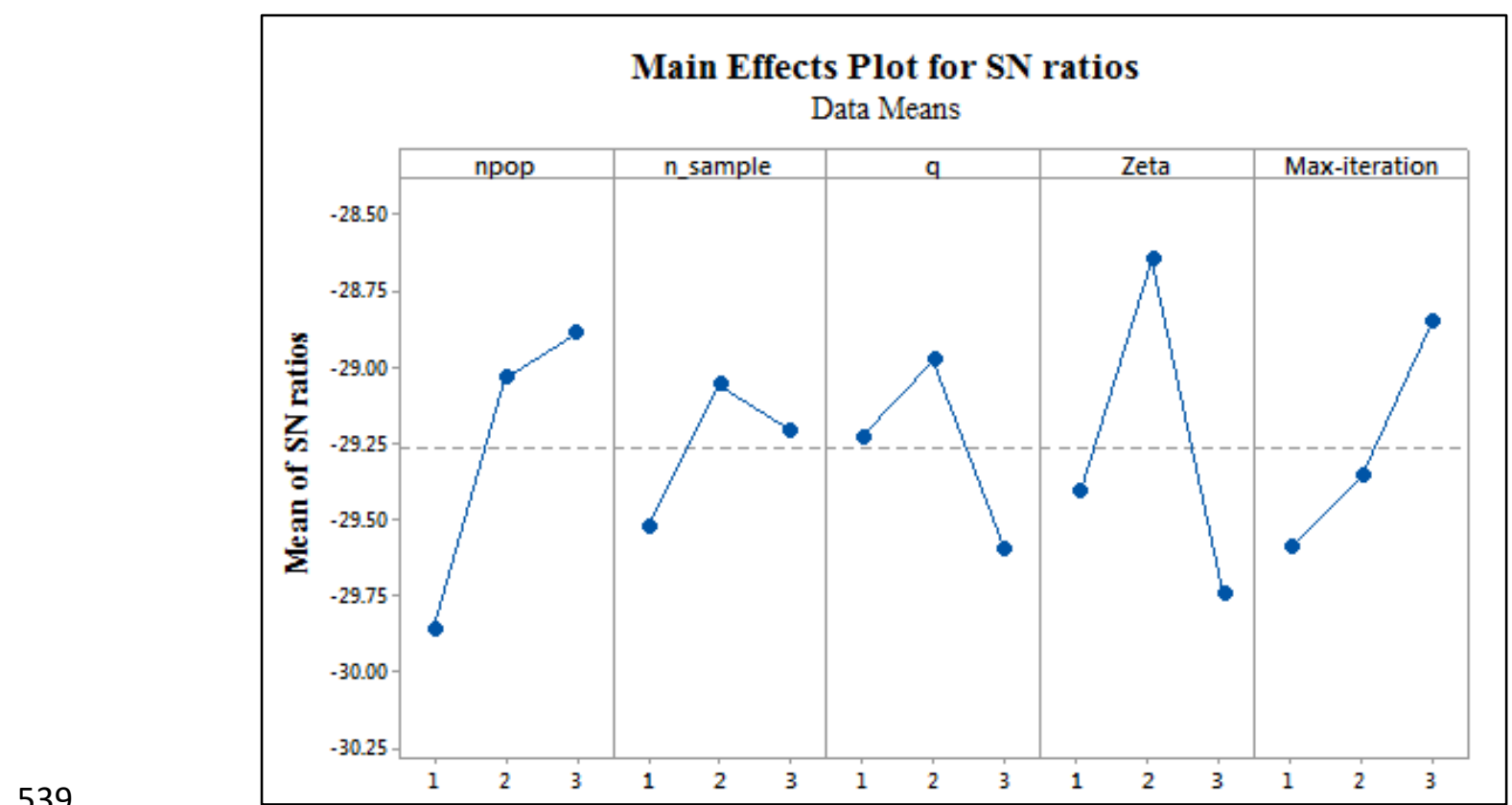

Fig. 10 Signal to noise ratio diagram for multi-objective hybrid ACO-TLBO 


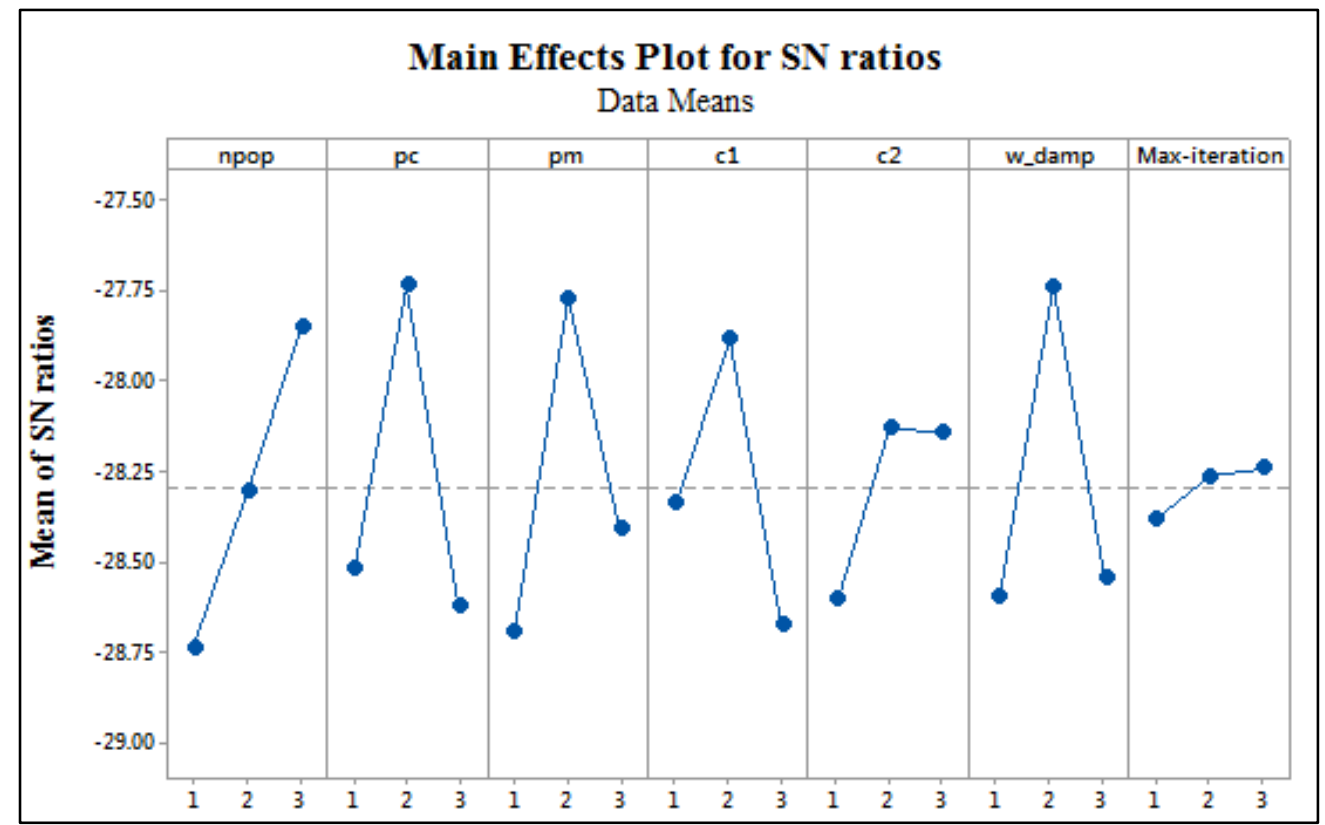

Fig. 11 Signal to noise ratio diagram for multi-objective hybrid improved GA-PSO

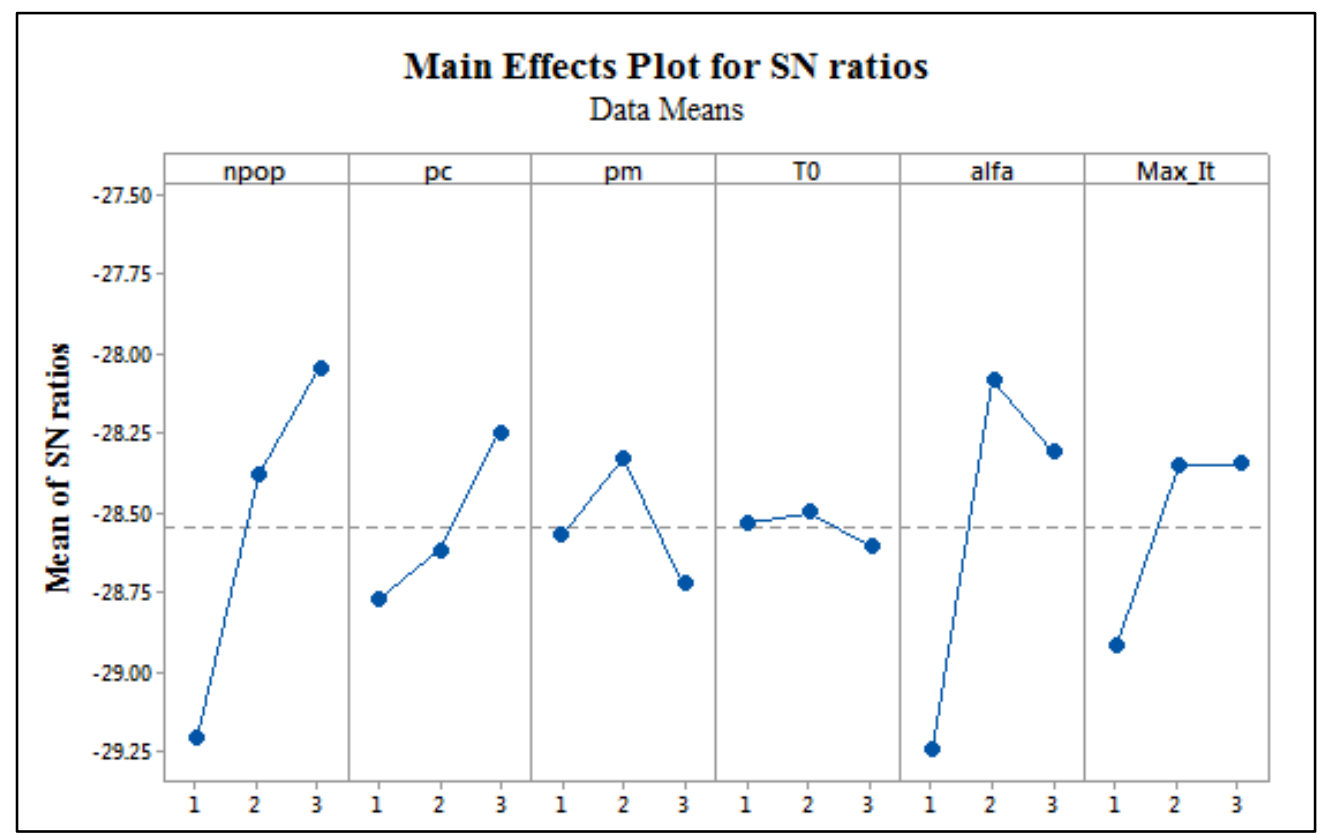

Fig. 12 Signal to noise ratio diagram for multi-objective hybrid improved GA-SA

Table 4 Parameter of propoed algorithms and their levels

\begin{tabular}{ccccc}
\hline \multirow{2}{*}{ Algorithms } & \multirow{2}{*}{ Parameters } & \multicolumn{3}{c}{ Parameter Level } \\
\cline { 3 - 5 } & $n_{\text {pop }}$ & Level 1 & Level 2 & Level 3 \\
\hline \multirow{4}{*}{ ACO-TLBO } & $n_{\text {sample }}$ & 50 & 100 & $\mathbf{1 5 0}$ \\
& $q$ & 10 & $\mathbf{1 5}$ & 20 \\
& $\zeta$ & 0.50 & $\mathbf{1 . 0 0}$ & 1.50 \\
& Max-iteration & $4 * \Psi$ & $\mathbf{1 . 0 0}$ & 1.50 \\
\multirow{4}{*}{ GA-PSO } & $n_{\text {pop }}$ & 50 & $6 * \Psi$ & $\mathbf{8} * \boldsymbol{\Psi}$ \\
& $p_{c}$ & 0.70 & 100 & $\mathbf{1 5 0}$ \\
& $p_{m}$ & 0.05 & $\mathbf{0 . 8 0}$ & 0.90 \\
& $c_{1}$ & 1.50 & $\mathbf{0 . 1 0}$ & 0.15 \\
& $c_{2}$ & 1.50 & $\mathbf{1 . 7 5}$ & 2 \\
\hline
\end{tabular}




\begin{tabular}{ccccc}
\hline & $w_{-}$damp & 0.99 & $\mathbf{0 . 9 5}$ & 0.90 \\
Max-iteration & $4 * \Psi$ & $6 * \Psi$ & $\mathbf{8} * \boldsymbol{\Psi}$ \\
\hline$n_{\text {pop }}$ & 50 & 100 & $\mathbf{1 5 0}$ \\
GA-SA & $p_{c}$ & 0.50 & 0.70 & $\mathbf{0 . 8 0}$ \\
& $p_{m}$ & 0.05 & $\mathbf{0 . 1 0}$ & 0.15 \\
& $T_{0}$ & 30 & $\mathbf{4 0}$ & 50 \\
& $\alpha$ & 0.99 & $\mathbf{0 . 9}$ & 0.88 \\
& Max-iteration & $6 * \Psi$ & $\mathbf{8} * \boldsymbol{\Psi}$ & $10 * \Psi$ \\
\hline
\end{tabular}

\section{Results and discussion}

In this section, the test problems and the case study are solved using proposed solution methods. Since the model is bi-objective, performance measures should be utilized to analyze and compare the performance of algorithms. The results are reported in Table 5, and also illustrated in Figures 13-18. In order to validate the algorithms, augmented $\varepsilon$-constraint method is used, which based on the results it is not able to solve medium and large-sized problems. 20 grid points was considered for the augmented $\varepsilon$-constraint (interested readers are referred to Mavrotas, 2009 for studying the details of augmented $\varepsilon$-constraint method). The considered time limit for all solution methods is 60000 seconds (NA means no answer could be found in the predetermined time limit). The spent CPU time for solving small-sized problems indicate the NP-hardness of the problem.

Table 5 Evaluation of proposed solution methods based on NPC and MID metrics

\begin{tabular}{|c|c|c|c|c|c|c|c|c|}
\hline \multirow{2}{*}{$\begin{array}{c}\text { Problem } \\
\text { no. }\end{array}$} & \multicolumn{4}{|c|}{ NPS } & \multicolumn{4}{|c|}{ MID } \\
\hline & $\begin{array}{c}\text { Aug. } \varepsilon^{-} \\
\text {constraint }\end{array}$ & GA-PSO & ACO-TLBO & GA-SA & $\begin{array}{c}\text { Aug. } \varepsilon^{-} \\
\text {constraint }\end{array}$ & GA-PSO & ACO-TLBO & GA-SA \\
\hline Case study & 20 & 22 & 18 & 20 & 0.89 & 0.92 & 0.89 & 0.95 \\
\hline 1 & 20 & 18 & 14 & 15 & 0.74 & 0.81 & 0.75 & 0.83 \\
\hline 2 & 20 & 17 & 15 & 17 & 0.68 & 0.76 & 0.72 & 0.79 \\
\hline 3 & 20 & 29 & 22 & 26 & 0.87 & 0.91 & 0.84 & 0.93 \\
\hline 4 & 20 & 26 & 25 & 23 & 0.78 & 0.87 & 0.78 & 0.89 \\
\hline 5 & NA & 24 & 21 & 22 & NA & 0.71 & 0.56 & 0.75 \\
\hline 6 & NA & 28 & 27 & 28 & NA & 0.76 & 0.57 & 0.79 \\
\hline 7 & NA & 34 & 25 & 31 & NA & 0.88 & 0.75 & 0.89 \\
\hline 8 & NA & 30 & 22 & 28 & NA & 0.78 & 0.67 & 0.79 \\
\hline 9 & NA & 32 & 29 & 31 & NA & 0.91 & 0.81 & 0.94 \\
\hline 10 & NA & 36 & 32 & 35 & NA & 1.06 & 0.92 & 1.12 \\
\hline 11 & NA & 25 & 19 & 22 & NA & 0.83 & 0.74 & 0.86 \\
\hline 12 & NA & 31 & 26 & 30 & NA & 0.69 & 0.60 & 0.79 \\
\hline Mean $\left(M_{\mathrm{i}}\right)$ & -- & 27.08 & 22.69 & 25.23 & -- & 0.84 & 0.74 & 0.87 \\
\hline$M_{\mathrm{i}}^{*}$ & \multicolumn{4}{|c|}{27.08} & $M_{\mathrm{i}}^{*}$ & \multicolumn{3}{|c|}{0.74} \\
\hline \multirow{2}{*}{$\begin{array}{c}\text { Problem } \\
\text { no. }\end{array}$} & \multicolumn{4}{|c|}{$\mathrm{QM}$} & \multicolumn{4}{|c|}{ DM } \\
\hline & $\begin{array}{c}\text { Aug. } \varepsilon^{-} \\
\text {constraint }\end{array}$ & GA-PSO & ACO-TLBO & GA-SA & $\begin{array}{c}\text { Aug. } \varepsilon^{-} \\
\text {constraint }\end{array}$ & GA-PSO & ACO-TLBO & GA-SA \\
\hline Case study & 0.49 & 0.12 & 0.29 & 0.10 & 259995.58 & 256623.41 & 257780.68 & 251438.45 \\
\hline 1 & 0.73 & 0.45 & 0.65 & 0.40 & 291300.85 & 265423.12 & 286703.85 & 215369.12 \\
\hline 2 & 0.68 & 0.45 & 0.57 & 0.28 & 375601.10 & 286346.56 & 309985.08 & 270005.36 \\
\hline 3 & 0.53 & 0.25 & 0.45 & 0.18 & 412256.45 & 316413.21 & 322398.65 & 304986.77 \\
\hline 4 & 0.45 & 0.16 & 0.23 & 0.12 & 482001.22 & 376251.12 & 381211.41 & 340365.85 \\
\hline 5 & NA & 0.35 & 0.47 & 0.18 & NA & 621511.19 & 649325.82 & 612895.32 \\
\hline 6 & NA & 0.44 & 0.25 & 0.31 & NA & 676252.90 & 690210.37 & 655211.23 \\
\hline 7 & NA & 0.36 & 0.68 & 0.23 & NA & 730230.56 & 749510.61 & 710320.80 \\
\hline 8 & NA & 0.45 & 0.61 & 0.25 & NA & 782521.64 & 791265.59 & 762941.40 \\
\hline 9 & NA & 0.39 & 0.47 & 0.14 & NA & 1262310.85 & 1252303.48 & 1002103.25 \\
\hline 10 & NA & 0.64 & 0.70 & 0.32 & NA & 1450362.67 & 1452389.01 & 1262300.85 \\
\hline 11 & NA & 0.43 & 0.54 & 0.12 & NA & 1562542.06 & 1626402.60 & 1414365.70 \\
\hline 12 & NA & 0.38 & 0.66 & 0.24 & NA & 1625321.94 & 1823563.12 & 1772003.81 \\
\hline Mean $\left(M_{\mathrm{i}}\right)$ & -- & 0.37 & 0.51 & 0.22 & -- & 785547.02 & 814850.02 & 736485.22 \\
\hline$M_{\mathrm{i}}^{*}$ & \multicolumn{4}{|c|}{0.51} & \multicolumn{4}{|c|}{814850.02} \\
\hline \multirow{2}{*}{$\begin{array}{c}\text { Problem } \\
\text { no. }\end{array}$} & \multicolumn{4}{|c|}{ SPM } & \multicolumn{4}{|c|}{ CPU time } \\
\hline & $\begin{array}{c}\text { Aug. } \varepsilon^{-} \\
\text {constraint }\end{array}$ & GA-PSO & ACO-TLBO & GA-SA & $\begin{array}{c}\text { Aug. } \varepsilon^{-} \\
\text {constraint }\end{array}$ & GA-PSO & ACO-TLBO & GA-SA \\
\hline Case study & 0.49 & 0.69 & 0.40 & 0.36 & 58632.12 & 825.12 & 891.19 & 756.17 \\
\hline 1 & 0.37 & 0.39 & 0.34 & 0.38 & 44250.23 & 615.96 & 712.12 & 520.13 \\
\hline 2 & 0.46 & 0.42 & 0.45 & 0.41 & 49532.65 & 701.32 & 744.23 & 636.99 \\
\hline 3 & 0.41 & 0.48 & 0.45 & 0.42 & 54465.23 & 798.23 & 845.60 & 710.45 \\
\hline 4 & 0.40 & 0.35 & 0.37 & 0.39 & 58128.90 & 1068.46 & 1126.31 & 938.16 \\
\hline 5 & NA & 0.42 & 0.38 & 0.45 & NA & 1550.51 & 1890.24 & 1382.36 \\
\hline 6 & NA & 0.47 & 0.51 & 0.45 & NA & 1778.65 & 2076.32 & 1901.27 \\
\hline 7 & NA & 0.59 & 0.48 & 0.54 & NA & 2450.32 & 2509.95 & 2250.42 \\
\hline 8 & NA & 0.42 & 0.39 & 0.37 & NA & 2968.12 & 3184.29 & 2551.45 \\
\hline
\end{tabular}




\begin{tabular}{|c|c|c|c|c|c|c|c|c|}
\hline 9 & NA & 0.28 & 0.25 & 0.31 & NA & 4680.19 & 4813.74 & 4262.23 \\
\hline 10 & NA & 0.56 & 0.41 & 0.48 & NA & 5482.13 & 5923.11 & 5320.85 \\
\hline 11 & NA & 0.47 & 0.39 & 0.42 & NA & 6212.85 & 6754.12 & 6088.71 \\
\hline 12 & NA & 0.40 & 0.38 & 0.44 & NA & 7152.23 & 7665.43 & 6950.65 \\
\hline Mean $\left(M_{\mathrm{i}}\right)$ & -- & 0.46 & 0.40 & 0.42 & -- & 2791.08 & 3010.51 & 2636.14 \\
\hline$M_{\mathrm{i}}^{*}$ & \multicolumn{4}{|c|}{0.40} & \multicolumn{4}{|c|}{2636.14} \\
\hline
\end{tabular}

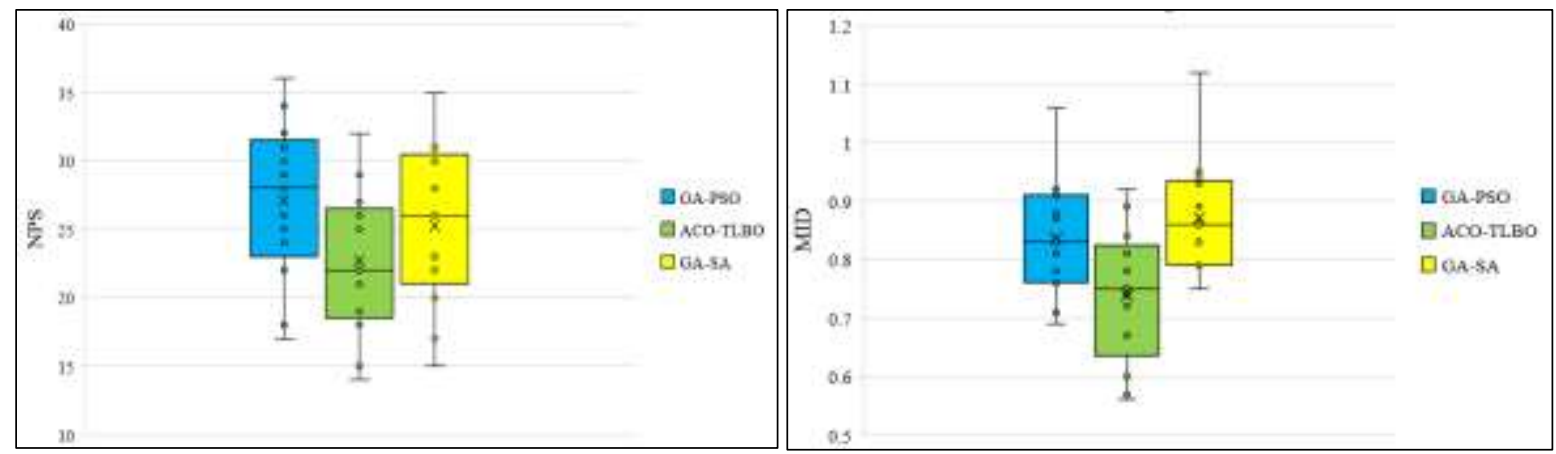

Fig.13 Comparing solution methods based on NPS

Fig. 14 Comparing solution methods based on MID
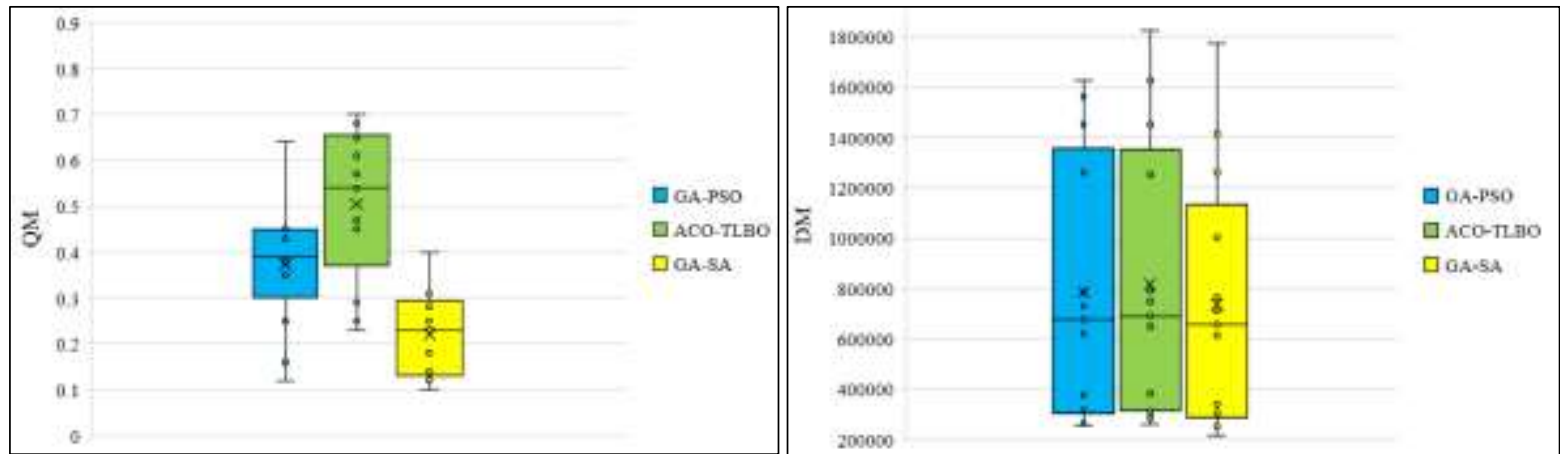

Fig. 15 Comparing solution methods based on QM

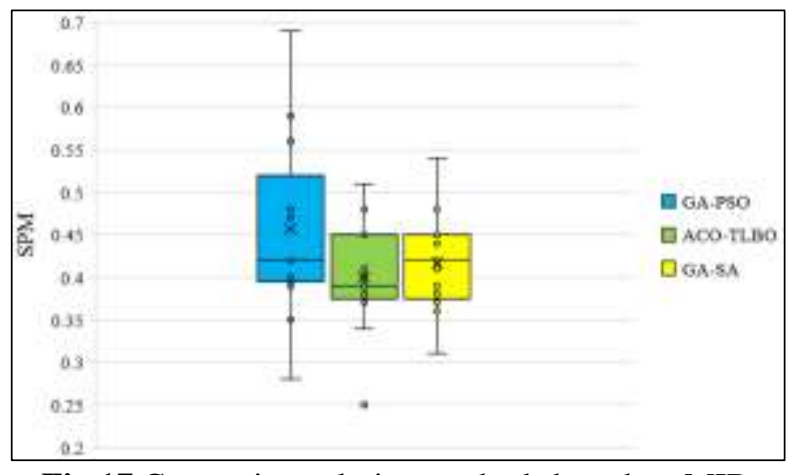

Fig.17 Comparing solution methods based on MID
Fig. 16 Comparing solution methods based on MID

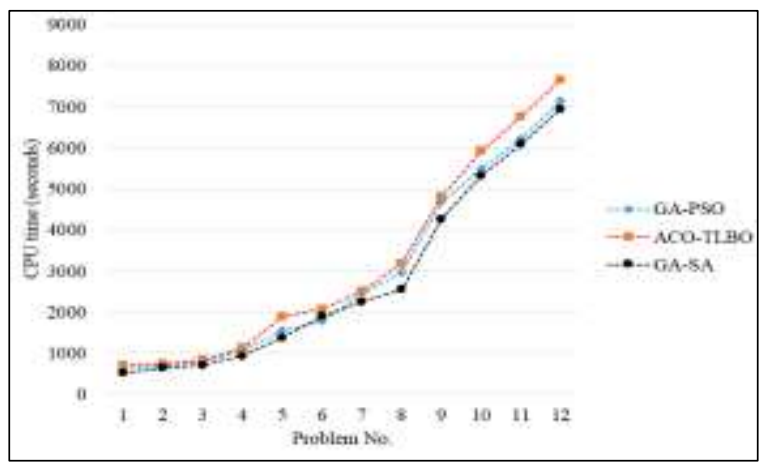

Fig. 18 Comparing solution methods based on MID

In order to determine the best algorithm, filtering/displaced ideal solution (DIS) method is applied (Pasandideh et al., 2015). For implementing this method, at first the values of $M_{i}$, which is the average of problems per each performance metric, are computed for each algorithm. Then, the ideal solution $\left(M_{i}^{*}\right)$ is determined which is the best value of $M_{i}$ among algorithms in each metric. After that, the values of $M_{i}$ should be normalized $\left(M_{i}^{N}=\right.$ $\frac{M_{i}-M_{i}^{*}}{N}, N$ : number of problems). Finally the direct distance for each solution method is computed by equation (59). The best method has the smallest value of direct distance. These values are presented in Table 6. According the obtained values, ACO-TLBO is selected as the best solution method, for it has the smallest value of direct distance. The Pareto fronts of the three algorithms for the case study problem is given in Figure 19. Figure 20 represents the location of existing and potential facilities and also the selected locations of the SC network related to the case study. 
Table 6 Values of $M_{i}^{N}$ and direct distance

\begin{tabular}{cccc}
\hline \multirow{2}{*}{ Metrics } & \multicolumn{3}{c}{ Algorithms } \\
\cline { 2 - 4 } & GA-PSO & ACO-TLBO & GA-SA \\
\hline NPS & 0.000 & -0.162 & -0.068 \\
MID & 0.134 & 0.000 & 0.179 \\
QM & -0.259 & 0.000 & -0.542 \\
DM & -0.036 & 0.000 & -0.096 \\
SPM & 0.142 & 0.000 & 0.042 \\
CPU & 0.059 & 0.142 & 0.000 \\
\hline Direct distance & 0.630 & 0.304 & 0.927 \\
\hline
\end{tabular}

575

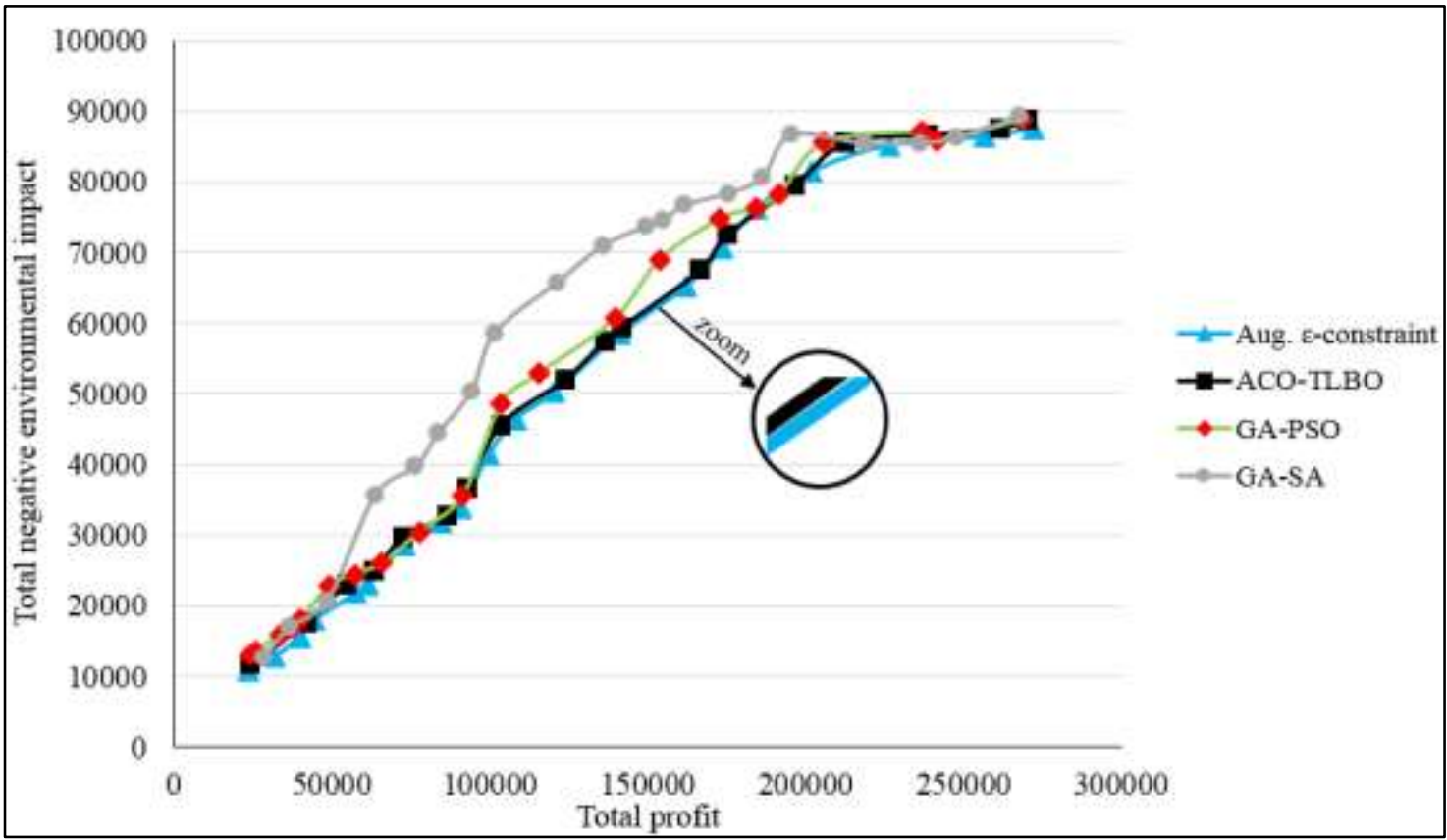

Fig.19 Pareto fronts obtained by solution methods for the problem of case study 


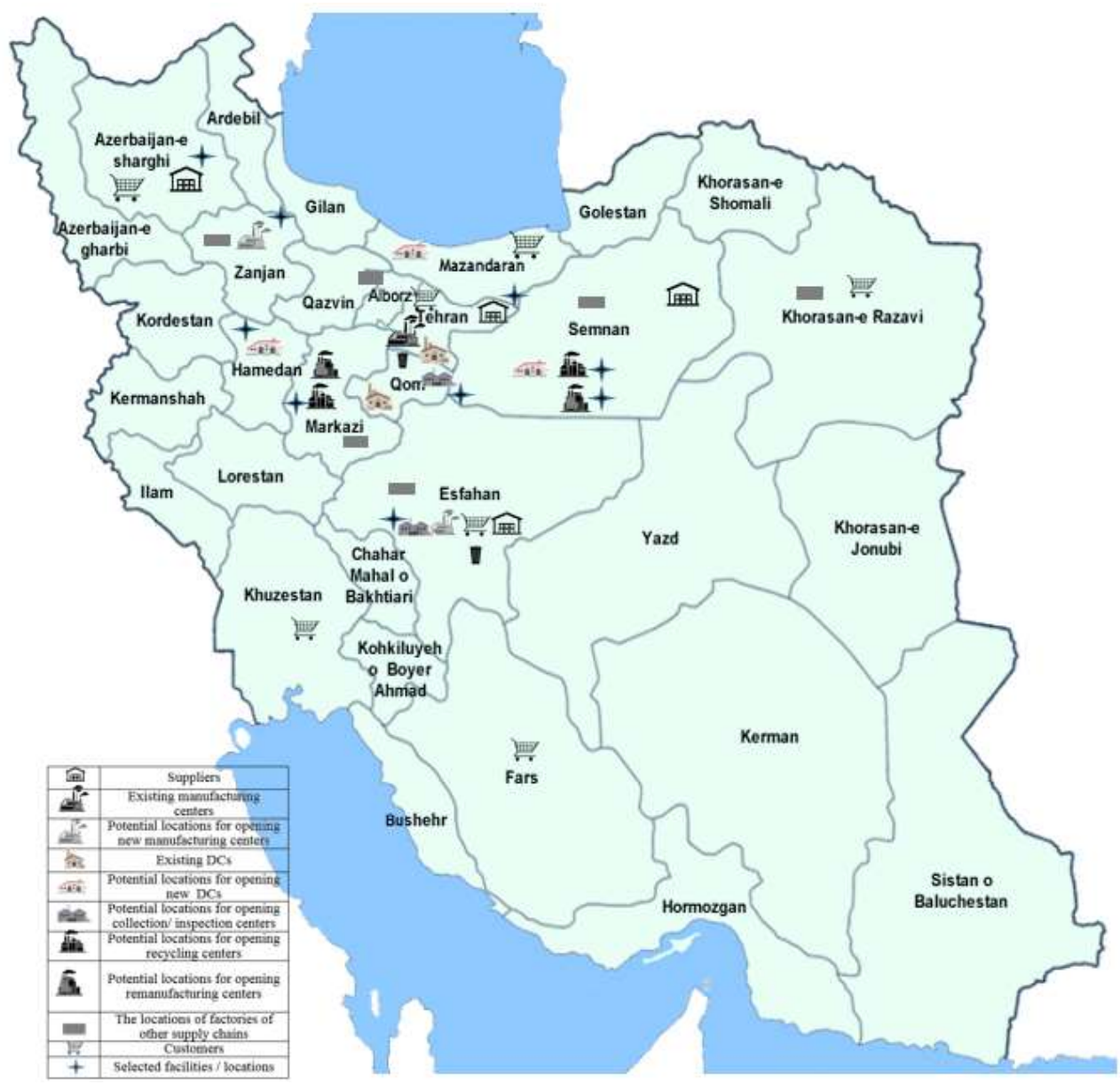

Fig. 20 Map of Iran and the location of facilities and other components of the supply chain network related to the case study

As mentioned before, in this paper it is assumed that SC network is under disruption risks, and some resilience strategies are applied to increase the SC resilience and cope with disruptions. In the following, the effects of resilience strategies on SC objectives are investigated. The problem related to the case study is chosen for doing the analyses. Figure 21 represent the impacts of resilience strategies on objective functions. Eight conditions are considered as follows:

- Condition 1: no resilience strategy is applied except multiple sourcing.

- Condition 2: multiple sourcing and facility fortification strategies are applied.

- Condition 3: multiple sourcing and capacity expansion strategies are applied.

- Condition 4: multiple sourcing and dual-channel distribution strategies are applied.

- Condition 5: multiple sourcing and dynamic pricing strategies are applied.

- Condition 6: multiple sourcing and lateral transshipment strategies are applied.

- Condition 7: multiple sourcing and using backup vehicles strategies are applied.

- Condition 8: All resilience strategies are applied. 


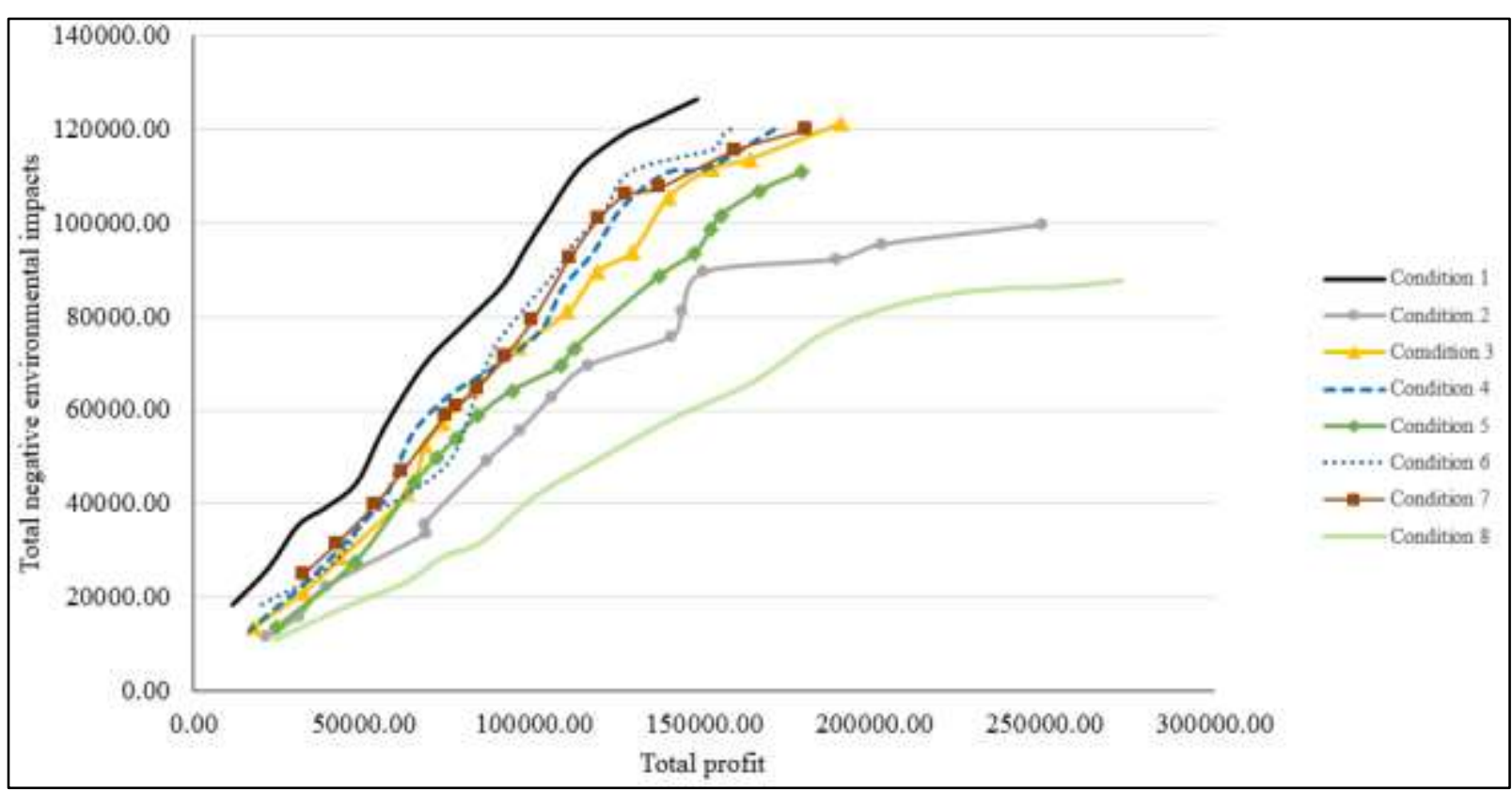

Fig. 21 Investigating the effect of resilience on supply chain objectives

As can be observed from obtained Pareto fronts, resilience strategies have substantial effect on objectives. On the first objective function, and on average, facility fortification by $46 \%$, dynamic pricing by $39 \%$, capacity expansion by $27 \%$, using backup vehicles by $24 \%$, lateral transshipment by $23 \%$ and dual-channel distribution by $17 \%$ improves the SC profit in comparison with the non-resilient condition (Condition 8). Moreover utilizing all strategies enhance the SC profit by $82 \%$ on average. On the second objective function, facility fortification by $21 \%$, dynamic pricing by $9 \%$, dual-channel distribution by $6 \%$, capacity expansion by $5 \%$, using backup vehicles by $4 \%$, lateral transshipment by $1 \%$ and finally using all strategies simultaneously decreases the SC negative environmental impacts by $28 \%$. Figure 22 depicts the objective functions under the considered conditions. In Figure 22(a) the first objective function is optimized without considering the second one, and in Figure 22(b) this work is done for the second objective function. The outputs confirm the effectiveness of resilience strategies.

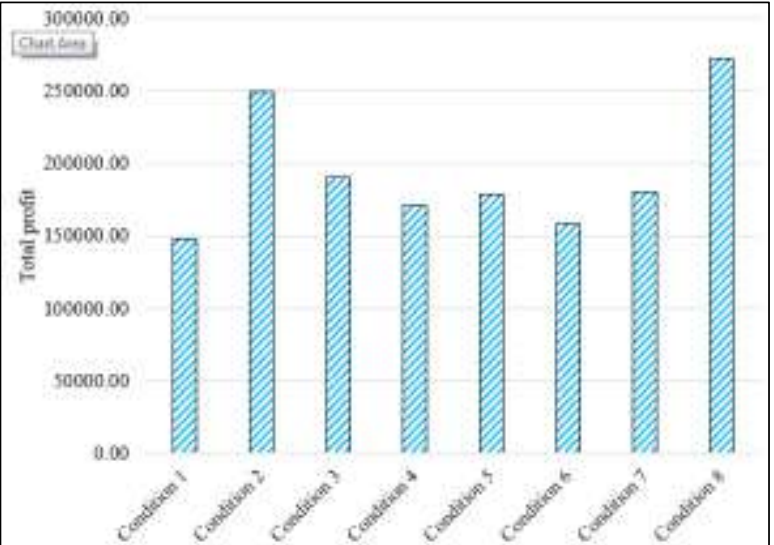

a

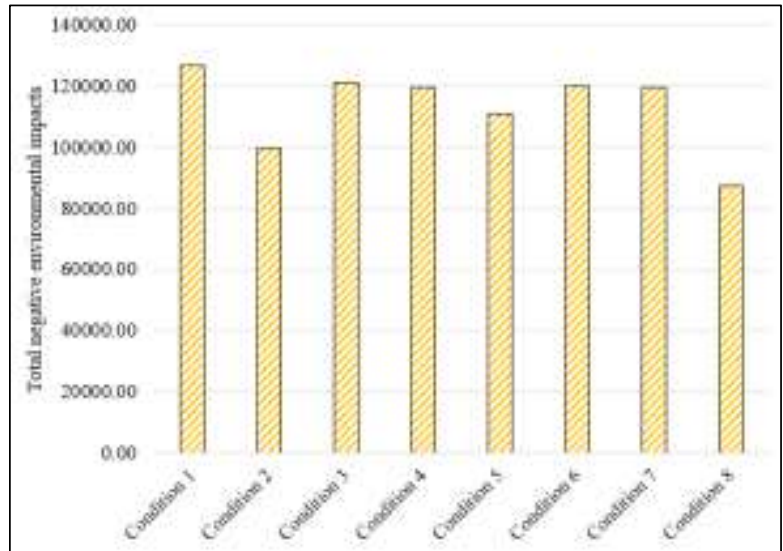

b

Fig. 22 Investigating the effects of resileince strategies on The first objective (a) and the second objective (b)

The values of the recycled materials and released/disposed EOL products are represented in Figure 23. As can be are consumed than in non-resilient condition (condition 1). Also, in non-resilient mode, more EOL products remain in the environment. Thus, the protection of natural resources in the non-resilient mode is much less and the environmental pollution in this state is much more. All in all, it is concluded that resilience is necessary for a supply chain to be green. 


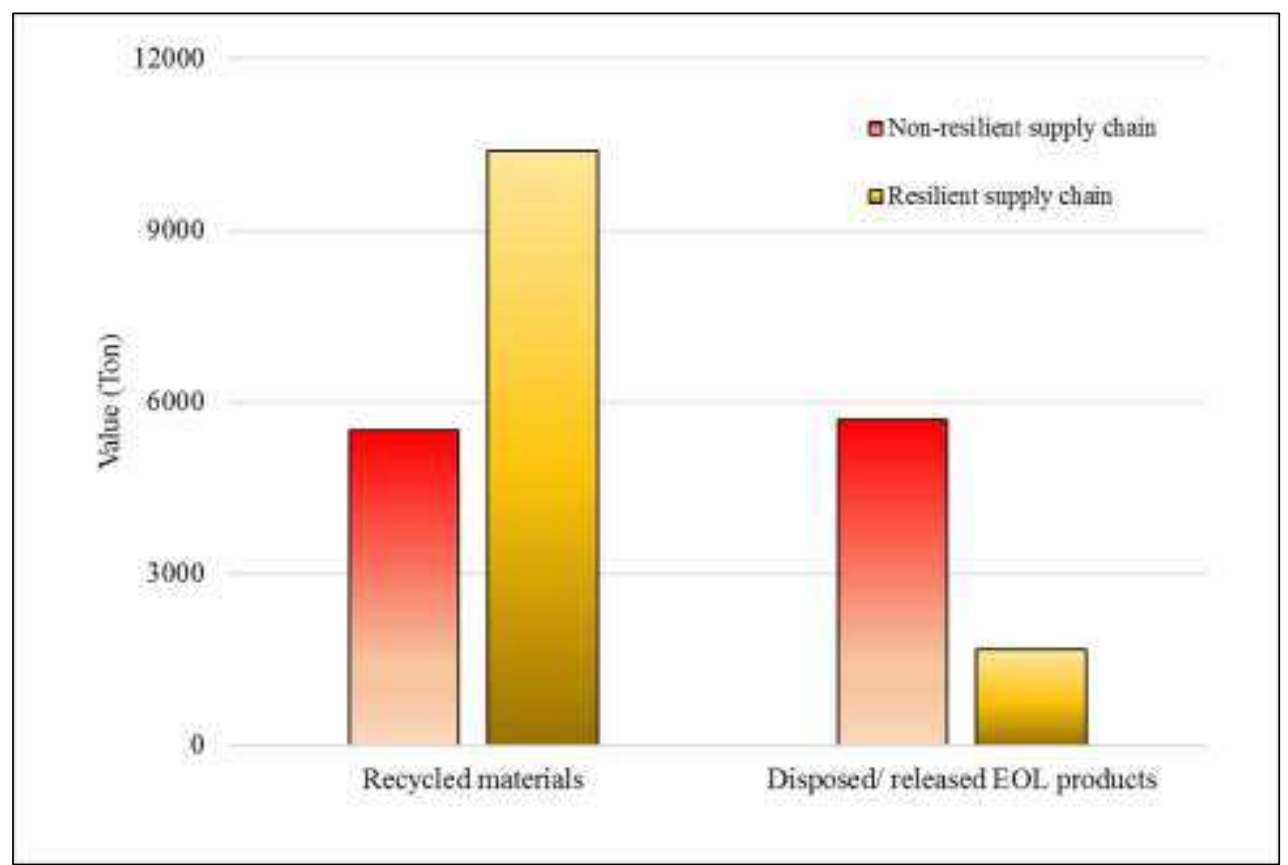

620 At the end of this section, a sensitivity analysis is done on responsiveness rate. Figures 24 and 25 show the values objective functions based on the different values of responsiveness rate (for main, remanufactured and recycled products). In each figure, the related objective function is optimized without considering the other objective.

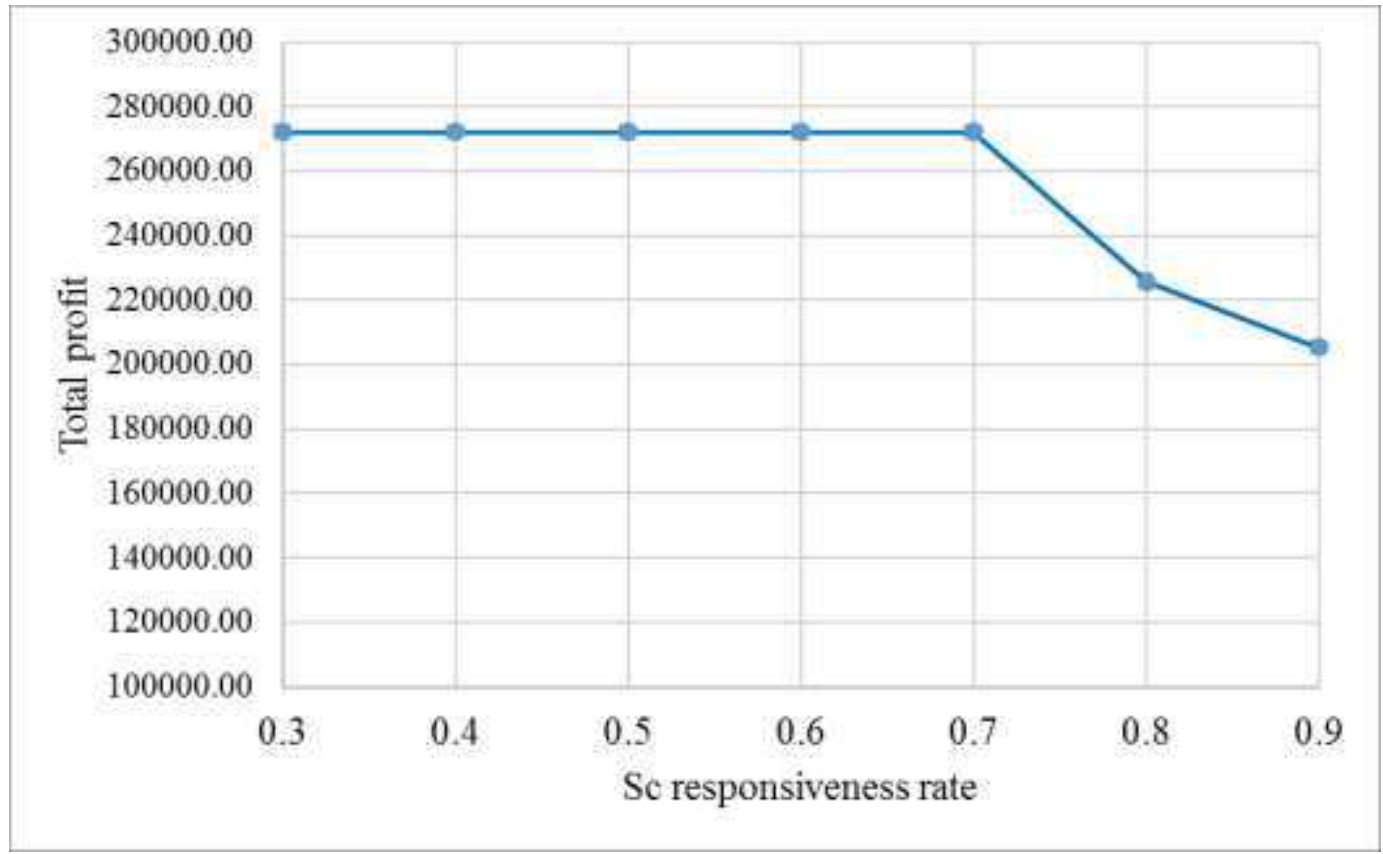

Fig. 24 Changes in the first objective function values for different SC responsiveness rates 


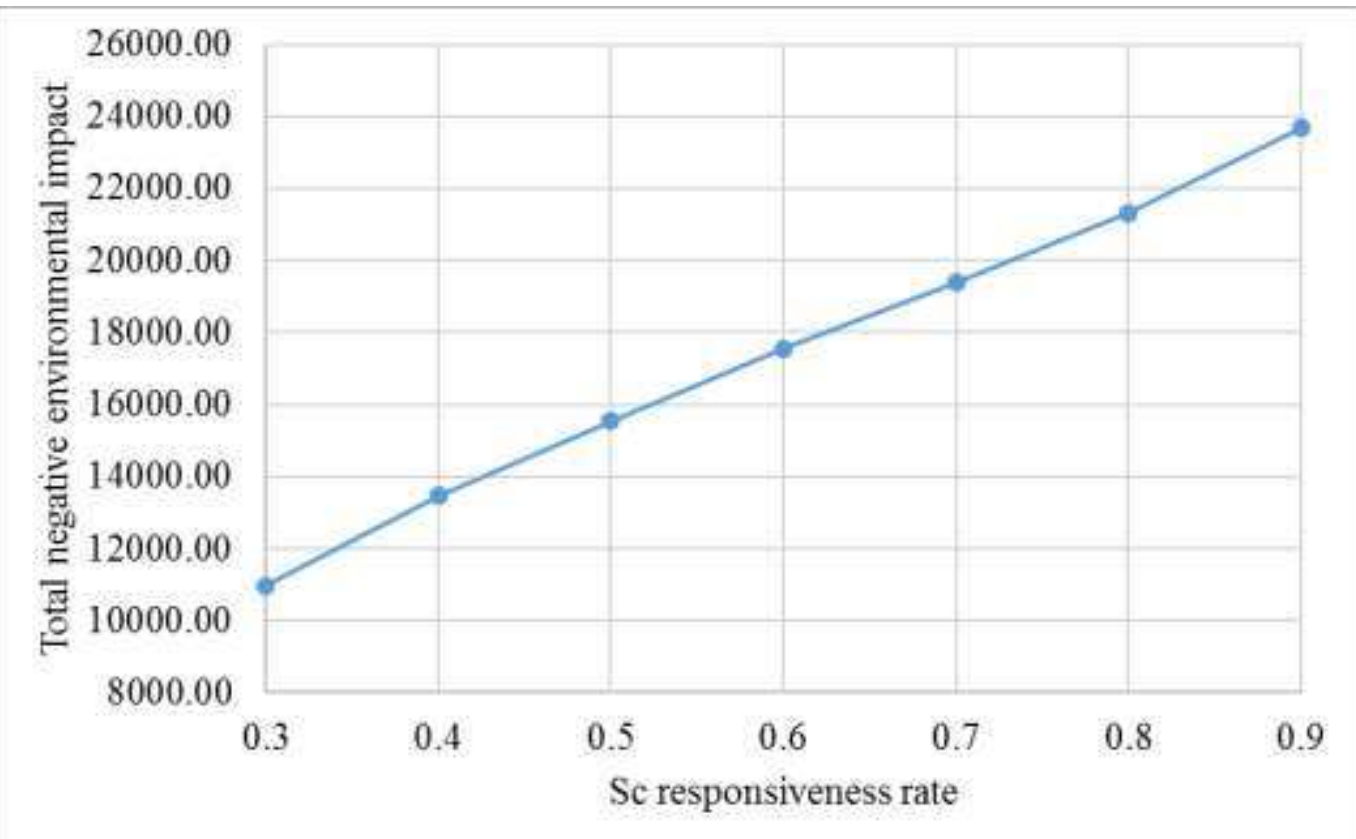

Fig. 25 Changes in the second objective function values for different SC responsiveness rates

The outputs meet our expectations and are logical. Given that the first objective function is profit maximization, in responsiveness rates between 0.3 to 0.7 , since the supply chain is able to meet customer demand up to about $70 \%$ (Note the constraints of responsiveness), the amount of objective function is constant in this range. With increasing responsiveness rate, the supply chain is not able to meet demand, and shortage costs increases and consequently, supply chain profitability is reduced. Regarding the second objective function, which is to minimize the negative environmental effects, it can be said that the problem seeks to reduce production and other activities in order to reduce the objective function, but the constraints on responsiveness rate prevent the objective function to reach near zero values. Furthermore, as the responsiveness rate increases, the amounts of production, transportation, and other activities increase, and consequently the second objective function deteriorates.

\section{Managerial insights}

The case study for the problem studied in this paper is in the tire industry. However, the presented model is general and can be used in other industries with slight changes. Managers and engineers of the tire industry and other industries can get insight from the problem under study to identify disruption and operational risks of their supply chain and use the presented stochastic model and resilience strategies to deal with them. They should note that when disruption occurs for SC facilities, the company has problems in the production of products and delivering them to customers. Subsequently, Due to the company's inability to meet customers' demands, shortage costs increase and sales revenues decrease, and the company may suffer losses. On the other hand, having weakness in resilience of the supply chain network, the negative environmental effects increase. The first reason is that as the capacity of the supply chain decreases, more new facilities must be established to respond to demands. Also, with the reduction of facility capacity and the opening of new facilities, the amount of transportation will increase. On the other hand, with the occurrence of disruptions, the reverse logistics activities are reduced or stopped, and consequently more EOL products are released in environment or disposed, and more raw materials are consumed to produce the products, so the the negative environmental effects increase. Resilience strategies can help in mitigation of these negative impacts.

The proposed model will help the relevant managers and engineers in selecting suppliers, choosing the location of facilities, determining the flow of materials and products between facilities and pricing products. Managers can use the Pareto fronts provided by the solution methods to select a point to achieve their desired conditions in the economic and environmental dimensions based on the policies and guidelines of their company. This study can be utilized as a guide by companies to withstand disruptions and maintain their economic and environmental objectives and be responsive. 


\section{Conclusion}

662 Today, various disruptions threaten the survival and efficiency of supply chains. Environmental and economic objectives of supply chains that are important to stakeholders can be degraded by disruptions. Therefore, paying attention to supply chain resilience against disruptions is very important to protect the objectives. In this paper, the issue of green and resilient supply chain network design was investigated. The structure of the studied supply chain network was mixed open and closed-loop, and operational and disruption risks were taken into account. Resilience strategies were applied to mitigate the disruption risks, and the uncertainty of the problem was handled via scenario-based two-stage stochastic programming approach. Due to the high complexity of the problem, a new hybrid metaheuristic called ACO-TLBO was developed. Two other hybrid metaheuristics including hybrid improved GA-PSO and hybrid improved GA-SA were proposed to solve the problem and compare the solution methods. Also, augmented $\varepsilon$-constraint method was applied to verify the algorithms. The parameters of the metaheuristics were tuned by Taguchi method and then the proposed metaheuristics were compared using various test problems. Based on the comparisons and the results of the 'filtering/displaced ideal solution' method, ACOTLBO algorithm was identified as the best one. A real case study in the tire industry was presented for further analyses and to show the applicability and validity of the model and solution methods. The results of analyses showed that the introduced resilience strategies are very effective and can significantly improve the economic and environmental objective functions compared to the non-resilient mode. The analyses on resilience strategies were based on 8 conditions. The results showed that applying all proposed resilience strategies can increase SC profit by $82 \%$ and decrease the negative environmental impacts by $28 \%$. Overall, the outputs also proved that considering resilience alongside environmental aspects is essential. The sensitivity analysis on responsiveness rate demonstrated the correct performance of the model and the importance of this parameter. The mathematical model, the solution methods and the obtained results can be useful for managers and related engineers.

There are some directions and suggestions for future research that can be followed for extending the field of resilient SCND. Considering other objectives for the studied problem like the social sustainability objective and solving tri-objective optimization problem can be a good suggestion for future research. Another opportunity for future studies is developing exact solution methods or other metaheuristics for solving the developed model. Finally, considering other types of uncertainties like deep and epistemic types can be an interesting suggestion for researchers interested in optimizing SC networks under uncertainty.

\section{Author contribution}

All authors contributed to the study conception and design. The contributions related to each author are as follows: Mohammad Mahdi Vali-Siar: Conceptualization, Methodology, Software, Validation, Investigation, WritingOriginal Draft, Visualization

Emad Roghanian: Conceptualization, Review \& editing, Supervision

Both authors read and approved the final manuscript.

Data availability The authors declare that the data are not available and can be presented upon the requested of the readers.

Funding The authors declare that no funds, grants, or other support were received during the preparation of this manuscript

\section{Declarations}

\section{Ethical approval Not applicable}

Consent to participate Not applicable

Consent for publication Not applicable

Competing interests The authors have no relevant financial or non-financial interests to disclose 


\section{References}

Azad, N., Saharidis, G.K., Davoudpour, H., Malekly, H. and Yektamaram, S.A., 2013. Strategies for protecting supply chain networks against facility and transportation disruptions: an improved Benders decomposition approach. Annals of Operations Research, 210(1), pp.125-163.

Boronoos, M., Mousazadeh, M. and Torabi, S.A., 2021. A robust mixed flexible-possibilistic programming approach for multi-objective closed-loop green supply chain network design. Environment, Development and Sustainability, 23(3), pp.3368-3395.

Bottani, E., Murino, T., Schiavo, M. and Akkerman, R., 2019. Resilient food supply chain design: Modelling framework and metaheuristic solution approach. Computers \& Industrial Engineering, 135, pp.177-198.

Deb, K., Pratap, A., Agarwal, S. and Meyarivan, T.A.M.T., 2002. A fast and elitist multiobjective genetic algorithm: NSGA-II. IEEE transactions on evolutionary computation, 6(2), pp.182-197.

Dorigo, M., 1992. Optimization, Learning and Natural Algorithms (in Italian). Ph.D. thesis, Dipartimento di Elettronica, Politecnico di Milano, Italy.

Dorigo, M., Di Caro, G. and Gambardella, L.M., 1999. Ant algorithms for discrete optimization. Artificial life, 5(2), pp.137-172.

Dorigo, M., Maniezzo, V. and Colorni, A., 1996. Ant system: optimization by a colony of cooperating agents. IEEE Transactions on Systems, Man, and Cybernetics, Part B (Cybernetics), 26(1), pp.29-41.

Dorigo, M. and Stützle, T., 2004. Ant Colony Optimization. MIT Press, Cambridge, Massachusetts.

Fahimnia, B., Jabbarzadeh, A. and Sarkis, J., 2018. Greening versus resilience: A supply chain design perspective. Transportation Research Part E: Logistics and Transportation Review, 119, pp.129-148.

Fattahi, M., Govindan, K. and Keyvanshokooh, E., 2017. Responsive and resilient supply chain network design under operational and disruption risks with delivery lead-time sensitive customers. Transportation Research Part E: Logistics and Transportation Review, 101, pp.176-200.

Fattahi, M., Govindan, K. and Keyvanshokooh, E., 2018. A multi-stage stochastic program for supply chain network redesign problem with price-dependent uncertain demands. Computers \& Operations Research, 100, pp.314-332.

Fazli-Khalaf, M., Naderi, B., Mohammadi, M. and Pishvaee, M.S., 2021. The design of a resilient and sustainable maximal covering closed-loop supply chain network under hybrid uncertainties: a case study in tire industry. Environment, Development and Sustainability, 23(7), pp.9949-9973.

Gen, M., Altiparmak, F. and Lin, L., 2006. A genetic algorithm for two-stage transportation problem using priority-based encoding. OR spectrum, 28(3), pp.337-354.

Gholami-Zanjani, S.M., Klibi, W., Jabalameli, M.S. and Pishvaee, M.S., 2021a. The design of resilient food supply chain networks prone to epidemic disruptions. International Journal of Production Economics, 233, p.108001.

Gholami-Zanjani, S.M., Jabalameli, M.S. and Pishvaee, M.S., 2021b. A resilient-green model for multi-echelon meat supply chain planning. Computers \& Industrial Engineering, 152, p.107018.

Ghomi-Avili, M., Naeini, S.G.J., Tavakkoli-Moghaddam, R. and Jabbarzadeh, A., 2018. A fuzzy pricing model for a green competitive closed-loop supply chain network design in the presence of disruptions. Journal of Cleaner Production, 188, pp.425-442.

Govindan, K., Paam, P. and Abtahi, A.R., 2016. A fuzzy multi-objective optimization model for sustainable reverse logistics network design. Ecological indicators, 67, pp.753-768.

Govindan, K., Fattahi, M. and Keyvanshokooh, E., 2017. Supply chain network design under uncertainty: A comprehensive review and future research directions. European Journal of Operational Research, 263(1), pp.108-141.

Hasani, A. and Khosrojerdi, A., 2016. Robust global supply chain network design under disruption and uncertainty considering resilience strategies: A parallel memetic algorithm for a real-life case study. Transportation Research Part E: Logistics and Transportation Review, 87, pp.20-52.

Hasani, A., Mokhtari, H. and Fattahi, M., 2021. A multi-objective optimization approach for green and resilient supply chain network design: a real-life Case Study. Journal of Cleaner Production, 278, p.123199.

Holland, J. H. (1975). Adaption in natural and adaptive systems. Ann Arbor: University of Michigan Press.

Hosseini, S., Ivanov, D. and Dolgui, A., 2019. Review of quantitative methods for supply chain resilience analysis. Transportation Research Part E: Logistics and Transportation Review, 125, pp.285-307.

Ivanov, D. and Dolgui, A., 2020. Viability of intertwined supply networks: extending the supply chain resilience angles towards survivability. A position paper motivated by COVID-19 outbreak. International Journal of Production Research, 58(10), pp.2904-2915.

Jabbarzadeh, A., Fahimnia, B., Sheu, J.B. and Moghadam, H.S., 2016. Designing a supply chain resilient to major disruptions and supply/demand interruptions. Transportation Research Part B: Methodological, 94, pp.121149.

Jabbarzadeh, A., Fahimnia, B. and Sabouhi, F., 2018a. Resilient and sustainable supply chain design: sustainability analysis under disruption risks. International Journal of Production Research, 56(17), pp.59455968. 
Jabbarzadeh, A., Haughton, M. and Khosrojerdi, A., 2018b. Closed-loop supply chain network design under disruption risks: A robust approach with real world application. Computers \& industrial engineering, 116, pp.178-191.

Karimi, N., Zandieh, M. and Karamooz, H.R., 2010. Bi-objective group scheduling in hybrid flexible flowshop: a multi-phase approach. Expert Systems with Applications, 37(6), pp.4024-4032.

Karmaker, C.L., Ahmed, T., Ahmed, S., Ali, S.M., Moktadir, M.A. and Kabir, G., 2021. Improving supply chain sustainability in the context of COVID-19 pandemic in an emerging economy: Exploring drivers using an integrated model. Sustainable production and consumption, 26, pp.411-427.

Kennedy, J. and Eberhart, R., 1995, November. Particle swarm optimization. In Proceedings of ICNN'95international conference on neural networks (Vol. 4, pp. 1942-1948). IEEE.

Kirkpatrick, S., Gelatt, C.D. and Vecchi, M.P., 1983. Optimization by simulated annealing. science, 220(4598), pp.671-680.

Klibi, W., Martel, A. and Guitouni, A., 2010. The design of robust value-creating supply chain networks: a critical review. European Journal of Operational Research, 203(2), pp.283-293.

Kumar, P., Herbert, M. and Rao, S., 2017. Population based metaheuristic algorithm approach for analysis of multi-item multi-period procurement lot sizing problem. Advances in Operations Research, 2017.

Lawson, E, 2018. Recycling end-of-life tyres. https://www.biobasedpress.eu/2018/04/recycling-end-of-lifetyres/. (Accessed 12 November 2021).

Liao, T., Socha, K., de Oca, M.A.M., Stützle, T. and Dorigo, M., 2013. Ant colony optimization for mixedvariable optimization problems. IEEE Transactions on Evolutionary Computation, 18(4), pp.503-518.

Maghsoudlou, H., Kahag, M.R., Niaki, S.T.A. and Pourvaziri, H., 2016. Bi-objective optimization of a threeechelon multi-server supply-chain problem in congested systems: Modeling and solution. Computers \& Industrial Engineering, 99, pp.41-62.

Mardan, E., Govindan, K., Mina, H. and Gholami-Zanjani, S.M., 2019. An accelerated benders decomposition algorithm for a bi-objective green closed loop supply chain network design problem. Journal of Cleaner Production, 235, pp.1499-1514.

Mavrotas, G., 2009. Effective implementation of the $\varepsilon$-constraint method in multi-objective mathematical programming problems. Applied mathematics and computation, 213(2), pp.455-465.

Meng, J., Hu, X., Chen, P., Coffman, D.M. and Han, M., 2020. The unequal contribution to global energy consumption along the supply chain. Journal of environmental management, 268, p.110701.

Michalewicz, Z., Vignaux, G.A. and Hobbs, M., 1991. A nonstandard genetic algorithm for the nonlinear transportation problem. ORSA Journal on computing, 3(4), pp.307-316.

Mohammed, A., Harris, I., Soroka, A. and Nujoom, R., 2019. A hybrid MCDM-fuzzy multi-objective programming approach for a G-resilient supply chain network design. Computers \& Industrial Engineering, 127, pp.297-312.

Mohtashami, Z., Aghsami, A. and Jolai, F., 2020. A green closed loop supply chain design using queuing system for reducing environmental impact and energy consumption. Journal of cleaner production, 242, p.118452.

Moncayo-Martínez, L.A. and Zhang, D.Z., 2011. Multi-objective ant colony optimisation: A meta-heuristic approach to supply chain design. International Journal of Production Economics, 131(1), pp.407-420.

Namdar, J., Li, X., Sawhney, R. and Pradhan, N., 2018. Supply chain resilience for single and multiple sourcing in the presence of disruption risks. International Journal of Production Research, 56(6), pp.2339-2360.

Nurjanni, K.P., Carvalho, M.S. and Costa, L., 2017. Green supply chain design: A mathematical modeling approach based on a multi-objective optimization model. International Journal of Production Economics, 183, pp.421-432.

Pasandideh, S.H.R., Niaki, S.T.A. and Asadi, K., 2015. Optimizing a bi-objective multi-product multi-period three echelon supply chain network with warehouse reliability. Expert Systems with Applications, 42(5), pp.26152623.

Peng, P., Snyder, L.V., Lim, A. and Liu, Z., 2011. Reliable logistics networks design with facility disruptions. Transportation Research Part B: Methodological, 45(8), pp.1190-1211.

Rajesh, R., 2020. Network design for resilience in supply chains using novel crazy elitist TLBO. Neural Computing and Applications, 32(11), pp.7421-7437.

Ramezanian, R., Vali-Siar, M.M. and Jalalian, M., 2019. Green permutation flowshop scheduling problem with sequence-dependent setup times: a case study. International Journal of Production Research, 57(10), pp.33113333.

Rao, R.V., Savsani, V.J. and Vakharia, D.P., 2011. Teaching-learning-based optimization: a novel method for constrained mechanical design optimization problems. Computer-Aided Design, 43(3), pp.303-315.

Research and Markets, 2018. Automotive tire market to 2025 . https://www. researchandmarkets.com/research/5lv58g/global_automotive/. (Accessed 20 June 2021).

Rezapour, S., Farahani, R.Z. and Pourakbar, M., 2017. Resilient supply chain network design under competition: a case study. European Journal of Operational Research, 259(3), pp.1017-1035.

Roy, R. K, (2010). A primer on Taguchi method. Michigan: society of Manufacturing Engineers 
Sabouhi, F., Jabalameli, M.S., Jabbarzadeh, A. and Fahimnia, B., 2020. A multi-cut L-shaped method for resilient and responsive supply chain network design. International Journal of Production Research, 58(24), pp.73537381.

Sabouhi, F., Pishvaee, M.S. and Jabalameli, M.S., 2018. Resilient supply chain design under operational and disruption risks considering quantity discount: A case study of pharmaceutical supply chain. Computers \& Industrial Engineering, 126, pp.657-672.

Sabouhi, F., Jabalameli, M.S. and Jabbarzadeh, A., 2021. An optimization approach for sustainable and resilient supply chain design with regional considerations. Computers \& Industrial Engineering, 159, p.107510.

Sadeghi Rad, R., and Nahavandi, N., 2018. A novel multi-objective optimization model for integrated problem of green closed loop supply chain network design and quantity discount. Journal of cleaner production, 196, pp.1549-1565.

Salehi Sadghiani, N., Torabi, S.A. and Sahebjamnia, N., 2015. Retail supply chain network design under operational and disruption risks. Transportation Research Part E: Logistics and Transportation Review, 75, pp.95-114.

Salema, M.I.G., Barbosa-Povoa, A.P. and Novais, A.Q., 2007. An optimization model for the design of a capacitated multi-product reverse logistics network with uncertainty. European journal of operational research, 179(3), pp.1063-1077.

Sazvar, Z., Tafakkori, K., Oladzad, N. and Nayeri, S., 2021. A capacity planning approach for sustainable-resilient supply chain network design under uncertainty: A case study of vaccine supply chain. Computers \& Industrial Engineering, 159, p.107406.

Shabbir, M.S., Mahmood, A., Setiawan, R., Nasirin, C., Rusdiyanto, R., Gazali, G., Arshad, M.A., Khan, S. and Batool, F., 2021. Closed-loop supply chain network design with sustainability and resiliency criteria. Environmental Science and Pollution Research, pp.1-16.

Socha, K. and Dorigo, M., 2008. Ant colony optimization for continuous domains. European journal of operational research, 185(3), pp.1155-1173.

Soleimani, H. and Govindan, K., 2015. A hybrid particle swarm optimization and genetic algorithm for closedloop supply chain network design in large-scale networks. Applied Mathematical Modelling, 39(14), pp.39904012.

Soleimani, H., Govindan, K., Saghafi, H. and Jafari, H., 2017. Fuzzy multi-objective sustainable and green closedloop supply chain network design. Computers \& industrial engineering, 109, pp.191-203.

Subulan, K., Taşan, A.S. and Baykasoğlu, A., 2015. Designing an environmentally conscious tire closed-loop supply chain network with multiple recovery options using interactive fuzzy goal programming. Applied Mathematical Modelling, 39(9), pp.2661-2702.

Tan, K.C., Goh, C.K., Yang, Y.J. and Lee, T.H., 2006. Evolving better population distribution and exploration in evolutionary multi-objective optimization. European Journal of Operational Research, 171(2), pp.463-495.

Torabi, S.A., Namdar, J., Hatefi, S.M. and Jolai, F., 2016. An enhanced possibilistic programming approach for reliable closed-loop supply chain network design. International Journal of Production Research, 54(5), pp.1358-1387.

Vali-Siar, M.M. and Roghanian, E., 2020. Resilient mixed supply chain network redesign under operational and disruption risks: A case study. Journal of Industrial Engineering Research in Production Systems, 8(16), pp.113-135.

Van Engeland, J., Beliën, J., De Boeck, L. and De Jaeger, S., 2020. Literature review: Strategic network optimization models in waste reverse supply chains. Omega, 91, p.102012.

Yavari, M. and Zaker, H., 2019. An integrated two-layer network model for designing a resilient green-closed loop supply chain of perishable products under disruption. Journal of Cleaner Production, 230, pp.198-218.

Yavari, M., Enjavi, H. and Geraeli, M., 2020. Demand management to cope with routes disruptions in locationinventory-routing problem for perishable products. Research in Transportation Business \& Management, 37, p.100552.

Zare Mehrjerdi, Y. and Shafiee, M., 2021. A resilient and sustainable closed-loop supply chain using multiple sourcing and information sharing strategies. Journal of Cleaner Production, 289, p.125141.

Zarrat Dakhely Parast, Z., Haleh, H., Darestani, S.A. and Amin-Tahmasbi, H., 2021. Green reverse supply chain network design considering location-routing-inventory decisions with simultaneous pickup and delivery. Environmental Science and Pollution Research, pp.1-22.

Zhen, L., Huang, L. and Wang, W., 2019. Green and sustainable closed-loop supply chain network design under uncertainty. Journal of Cleaner Production, 227, pp.1195-1209.

Zohal, M. and Soleimani, H., 2016. Developing an ant colony approach for green closed-loop supply chain network design: a case study in gold industry. Journal of Cleaner Production, 133, pp.314-337. 